\title{
Assessment of the Physical Disturbance of the Northern European Continental Shelf Seabed by Waves and Currents.
}

\author{
J.N. Aldridge ${ }^{1 *}$, E.R. Parker ${ }^{1}$, L. Bricheno ${ }^{3}$, S. L. Green ${ }^{2}$, J. van der Molen ${ }^{1}$ \\ ${ }^{1}$ Centre for Environmental Fisheries and Aquaculture Science, Pakefield Road, Lowestoft, Suffolk, NR33 OHT, UK. \\ 2 British Geological Survey, Murchison House, West Mains Road, Edinburgh EH9 3LA \\ 3 Proudman Oceanographic Laboratory, 6 Brownlow Street, Liverpool, L3 5DA, UK. \\ *Corresponding author: John Aldridge, Cefas, Pakefield Rd, Lowestoft, NR33 0HT ++44 (0)1503 524349 \\ email: john.aldridge@cefas.co.uk
}

Keywords: seabed disturbance, bedforms, gravel, sand, mud, modelling

\begin{abstract}
Natural seabed disturbance was quantified by estimating the number of days in a year that movement of the seabed occurred due to waves and currents, taking into account the seabed characteristics. Disturbance over gravel substrates was based on the concept of a critical threshold for bed movement. For mud substrates disturbance was assessed on the basis of bed failure under extreme hydrodynamic stress. For sand beds the disturbance frequency could be calculated as a function of disturbance depth below the sediment surface by relating disturbance to the occurrence of small scale bedforms using established relationships for predicting ripple and megaripple height. The method was applied to the northern European Continental Shelf $\left(48^{\circ} \mathrm{N}\right.$ to $58.5^{\circ} \mathrm{N}$ and $10^{\circ} \mathrm{W}$ to $\left.10^{\circ} \mathrm{E}\right)$ using modelled annual wave and current forcing with a temporal resolution of one hour and spatial resolution of approximately 11 $\mathrm{km}$. At the broad scale highest levels of disturbance occurred in areas of high tidal stress where dune/megaripple type bedforms were predicted and in shallow regions exposed to waves with large fetch. However, the detailed distribution of disturbance showed a complex relationship between water depth, tidal stress, wave fetch and grain size. An assessment of the uncertainty in the results was made using a simple Monte Carlo approach and in general indicated a large spread in disturbance frequency values. This suggests that present predictive relationships need improvement if assessments of natural disturbance are to be made with confidence. Nevertheless the results give a broad understanding of the location and intensity of natural physical bed disturbance including a measure of the relative intensity between different regions. This has applications to management of the seabed where human impacts have to be assessed in the context of the underlying natural disturbance. Recommendations are given for further research that would help decrease the uncertainty in natural disturbance prediction.
\end{abstract}

\section{Introduction}

Physical disturbance of the seabed by waves and currents is an important factor influencing habitat and species distributions (Hall, 1994; Kostylev \& Hannah, 2007), benthic biogeochemical functioning (Trimmer et al., 2005), and the transport and potential burial of pollutants (Kershaw et al., 1999). It also provides the background against which the impact of human-induced disturbance needs to be assessed. In this paper a methodology is presented for quantifying natural seabed disturbance in terms of the number of days in a year physical disturbance occurs to a given sediment depth. The agents of natural disturbance are taken to be waves, tides and wind-driven currents and natural 'disturbance' is defined as movement of the seabed sediment resulting from hydrodynamic stress.

Natural seabed disturbance has been considered by a number of workers, mainly in the context of assessing anthropogenic impacts. Thus De Alteris et al. (1999) consider the proportion of time the seabed undergoes natural sediment movement in relation to trawling activity and the rate at which beam trawl scars were removed. Following a slightly different approach, Brown et al. (2005) suggest the relative impact of wave-induced seabed disturbance will be greater than that of beam trawling disturbance when the near-bed orbital velocity magnitude exceeds typical trawl speeds. Natural disturbance is also important in the definition and classification of marine habitats. Wave and current modelling was used in Hemer (2006) to derive maps of the frequency and magnitude of bed stress on the Australian continental shelf. Further developments in the same region (Hughes et al., 2010; Harris \& Hughes, 2012) consider the frequency of extreme bed stress events and the identification of ecologically disturbed regions, with application to habitat classification and biodiversity measures. In a similar application, Kostylev \& Hannah (2007) combine a number of factors, including total wave current bed stress to characterise disturbance and define habitat types for the Scotian Shelf and Bay of Fundy. 
The approach taken in this study partly follows Hemer (2006) in using wave and current modelling to predict frequency and magnitude of hydrodynamic stress. However, rather than focussing simply on bed stress, consideration is also given to the seabed response to this stress. Over sandy sediments this response is characterised by the formation of small scale bedforms where the bedform height can be used to define a depth of disturbance. For gravel substrates the critical erosion stress of the underlying sediment is taken into account. For muddy sediments, large scale bed failure related to extreme hydrodynamic bed stress is used as the criteria for disturbance. Since the methodology is based on a synthesis of existing work on wave and current interaction with the seabed, no independent validation of the prediction methods is presented. However, an assessment of the uncertainty in the results is made using a Monte Carlo approach with probability distribution derived from a subjective assessment of the uncertainty of the empirical relationships used. The methodology was applied to the north European continental shelf including the North Sea, English Channel, Irish and Celtic Seas.

The principal output is an estimate of the number of days in a year disturbance occurred (and for sandy substrates, to what depth below the sediment surface). This is expressed in terms of a median value together with an indication of the degree of uncertainty based on the Monte Carlo type simulations. For sandy sediments an additional result is a prediction of the occurrence of different bedform types with an indication of which are the most important for disturbance in a given location. Finally, an attempt is made to identify gaps in knowledge based on the experience of undertaking this study.

The results allow a broad understanding of the location and frequency of physical bed disturbance due to natural hydrodynamic processes. Such information may be useful for marine management if, for example, it is decided to confine disruptive activity to areas with higher levels of natural disturbance (on the assumption that these may be more resilient to anthropogenic disturbance) or, for seabed remediation, to focus on sites with little natural disturbance (as these may take longer to return to a recovered state without such intervention). Applications include the assessment of fishing impacts (Diesing et al., 2013), criteria for the selection of marine protected areas (FSBI, 2001), definitions of seabed integrity under the European Marine Strategy Framework directive (MSFD), as well as decisions on the licensing of the seabed for aggregate extraction (Eggleton et al., 2011), offshore energy development or the disposal of dredged material.

\section{Methods}

\subsection{Hydrodynamics}

Wave and currents were modelled on the European continental shelf in the region between $48^{\circ} \mathrm{N}$ and $58.5^{\circ} \mathrm{N}$ and $10^{\circ} \mathrm{W}$ to $10^{\circ} \mathrm{E}$ with a grid resolution of approximately $11 \mathrm{~km}(1 / 6$ degree east-west, $1 / 9$ of a degree north-south). Seabed sediment type and grain size information were available for a more limited area restricting the region for which disturbance calculations could be carried out (Figure 1). Simulations used here were for the year 2008. Depth mean tidal and wind driven currents were calculated using the POLCOMS model (Holt \& James, 2001) forced with 15 tidal constituents (Q1, 01, P1, S1, K1, 2N2, $42, \mathrm{~N} 2, v 2, \mathrm{M} 2, \mathrm{~L} 2, \mathrm{~T} 2, \mathrm{~S} 2, \mathrm{~K} 2$, M4) and hourly wind and pressure at $12 \mathrm{~km}$ resolution from the UK meteorological office mesoscale atmospheric model. Using the same meteorological forcing, the WAM spectral wave model (Osuna \& Wolf, 2004) was used to provide the root mean square (RMS) wave orbital velocity, mean zero crossing wave period $\left(T_{\mathrm{z}}\right)$, and wave direction at the bed. Both current and wave information were sampled at hourly intervals for subsequent calculations. Further details on model forcing and validation can be found in a companion paper (Bricheno et al., in prep). Validation consisted of a comparison with observed tidal constituent data for tidal heights and currents covering a representative geographical spread. Time series of seabed wave parameters have been compared with seabed lander data at two locations and surface wave heights compared with buoy data at a representative spread of stations covering the model domain.

The grain-related current stress $\left(\tau_{c}^{\prime}\right)$ was calculated from the depth-mean tidal velocity ( $\left.\mathbf{U}_{\mathbf{c}}\right)$ using a standard quadratic drag law with grain size related friction coefficient

$$
\begin{aligned}
& \text { Equation } 1 \tau_{c}^{\prime}=\rho C_{D}\left|\mathbf{U}_{c}\right|^{2} \\
& C_{D}=\left[\kappa /\left(\ln \left(30 h / k_{s}\right)-1\right)\right]^{2}
\end{aligned}
$$

where water density $\rho=1025 \mathrm{kgm}^{-3}$, von Karman constant $\kappa=0.4, \mathrm{~h}(\mathrm{~m})$ is the water depth, and bed roughness $k_{s}$ was related to the median seabed grain diameter $D_{50}$ by $k_{s}=2.5 D_{50}$. 
Many of the key empirical relationships for predicting wave related quantities, such as wave bed stress, thresholds for initial sediment movement, and predictions of sand ripple height, are derived from laboratory studies using monochromatic waves. A source of difficulty arises as the sea-state consists of a spectrum of waves and the wave parameters appearing in laboratory derived relationships needed to be related to some equivalent measure derived from the wave spectrum. The most commonly required parameters are the near bed velocity amplitude $U_{w}$ and the near bed wave period. Although there is no guarantee that results derived under single wave conditions do in fact hold under a wave spectrum, in various contexts workers have nevertheless suggested how this may be done. Thus Ockenden \& Soulsby (1994) recommend the wave orbital velocity of the equivalent monochromatic wave (the single frequency wave with the same energy density as the wave spectrum) for calculations of bed stress and bedload transport; Li \& Amos (1998) and Amos et al. (1999) use the orbital velocity based on the average of the largest $30 \%$ of the spectrum (so-called 'significant' wave velocity) to predict wave ripple heights; while O'Donoghue et al., (2006) make use of the average of the largest 10\% of the wave spectrum for the same purpose. In this study, unless otherwise specified, we use the velocity amplitude $\left(U_{w}\right)$ of the equivalent monochromatic wave (EMW) and the average zero-crossing period $\left(T_{\mathrm{z}}\right)$ at the bed for the wave period. $U_{w}$ is derived from the RMS wave orbital velocity as

$$
\text { Equation } 2 \quad U_{w}=\sqrt{2} u_{r m s}
$$

From these the near bed orbital excursion is given by

$$
\text { Equation } 3 \quad A_{w}=U_{w} T_{z} / 2 \pi
$$

The grain-related wave bed stress was calculated as $\tau^{\prime}{ }_{w}=1 / 2 \rho f_{w} U_{w}^{2}$. The friction factor $\left(f_{w}\right)$ used is the maximum of the smooth and rough turbulent friction factors given by Soulsby (1997, page 78). Where required, the combined grain-related wave-cycle maximum wave-current stress $\tau^{\prime}{ }_{w c}$ was calculated as a function of wave stress, currents stress and angle between waves and currents using the wave-current interaction model of Fredsøe (1984) as parameterised in Soulsby et al. (1993), Soulsby (1997).

The threshold condition for the movement of non-cohesive sediments is normally expressed in terms of the Shields number, derived from $\tau^{\prime}$ the skin friction component of total bed stress $\left(\mathrm{Nm}^{-2}\right)$,

$$
\text { Equation } 4 \quad \theta^{\prime}=\tau^{\prime} /\left[\rho(s-1) g D_{50}\right]
$$

where $S=\rho_{s} / \rho$ is the relative density of sediment $\rho_{\mathrm{s}}$ to the water density $\rho$ and $D_{50}$ is the median grain size of the bed. In this study the skin friction component of stress is approximated by the grain-related stress (Soulsby \& Whitehouse, 1995; Soulsby, 1997). Depending on the context the 'total' stress may be the current-only stress, wave-only stress or the combined maximum (over the wave period) wave-current stress. Sediment movement is assumed to occur when $\theta^{\prime}>\theta_{\text {crit }}$ where $\theta_{\text {crit }}$ is a grain-size dependent threshold. The form of $\theta_{\text {crit }}$ under currents, waves or combined flows has been the subject of many studies (for reviews see e.g. Buffington \& Montgomery, 1997; Paphitis, 2001). Various fits to the data have been proposed and we use the formulae presented in Soulsby (1997)

$$
\text { Equation } 5 \theta_{\text {crit }}=0.3 /\left(1+1.2 D_{*}\right)+0.055\left[1-\exp \left(-0.02 D_{*}\right)\right]
$$

where

$$
\text { Equation } 6 D_{*}=\sqrt[3]{g(s-1) / v^{2}} D_{50}
$$

is a non-dimensional median grain size ( $v$ is the kinematic viscosity). This will be referred to as the 'standard' Shields value. 


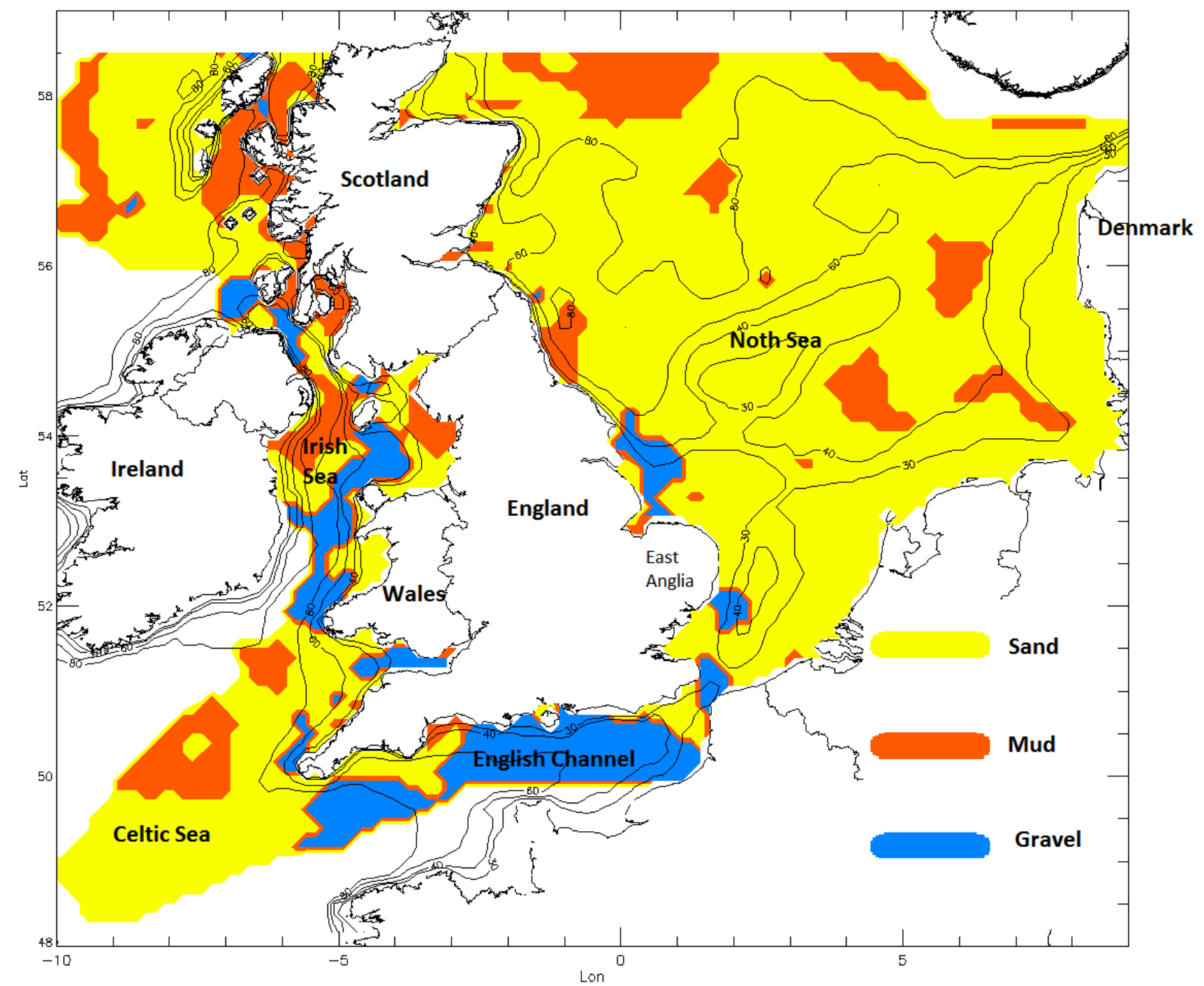

Figure 1: Bathymetry and bed substrate distribution used in this study. Bed substrate data from: i) North Sea benthos Survey, ii) The British Geological Survey and iii) Cefas.

\subsection{Seabed characteristics}

Surface sediment data were provided by the British Geological Survey (BGS) covering the UK sector of the North Sea and English Channel with a variable resolution averaging to around $5 \mathrm{~km}$ between sample stations. Additional information on gravel substrates in the English Channel (Coggan et al., 2012). was obtained from cruises carried out by the Centre for Environment Fisheries and Aquaculture Science Cefas In other regions, sediment type and grain size were obtained from the North Sea Benthos Survey (NSBS) (Basford et al., 1993) with distance between stations approximately $55 \mathrm{~km}$ and no data for the Norwegian trench. All data sets included a breakdown of the bed sediments into percentage mud, sand and gravel and median size for the sand grain fraction. Data collected by Cefas also included measurements of the grain size of the gravel fraction. A kriging technique implemented in the gstat package (Pebesma, 2004) was used to interpolate the data to the model grid.

For calculating natural bed disturbance, a distinction between mud, sand and gravel beds was assumed. It was decided that the response of heterogeneous bed types (e.g. muddy sand, sandy gravel) to wave and current stress is not sufficiently known to be able to make quantitative predictions. Therefore mixed beds were assigned to either mud, sand or gavel categories based on the following scheme: 


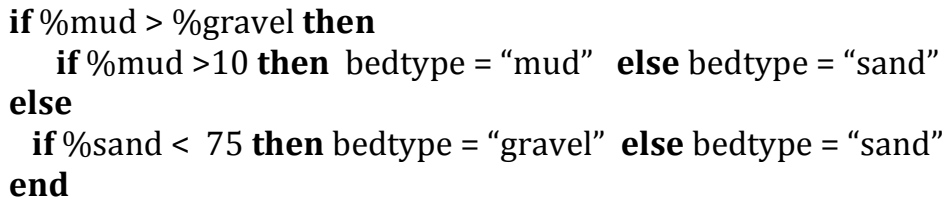

The resulting distributions of mud, sand and gravel (Figure 1) broadly reproduce published distributions (e.g., BGS maps; Jarke, 1956). Most regions classified as mud in Figure 1 are actually mud-sand mixtures. In the North Sea for example, most areas classified as mud had less than $20 \%$ mud content.

For the bed disturbance calculations the median sediment diameter is required. All datasets included the median size of the sand fraction. Only the Cefas data included size information on the gravel fractions. In order to estimate gravel size in regions where there were no measured values the Cefas data was used to derive a tentative relationship between the sand-gravel ratio $\gamma=\%$ gravel/(\%gravel $+\%$ sand) and the median diameter of the gravel fraction. The resulting relationship was of the form

$$
\text { Equation } 7 \quad \hat{D}_{\text {gravel }}=D_{0}+\left(D_{1}-D_{0}\right) \gamma^{R}
$$

where $D_{0}=5 \mathrm{~mm}, \mathrm{D}_{1}=55 \mathrm{~mm}$ and $\mathrm{R}=3.3$ and is plotted in Figure 2 . The overall median grain size in mixed sandgravel environments was then taken as the weighted mean $D_{50}=\gamma \hat{D}_{\text {gravel }}+(1-\gamma) D_{50 \text { (sand) }}$. For sediments classified as mud, the grain-size was taken as that of the volume weighted average of the median of the sand component with an assumed fine grain-size of $30 \mu \mathrm{m}$. The grain-size was then interpolated onto the calculation grid (Figure 3).

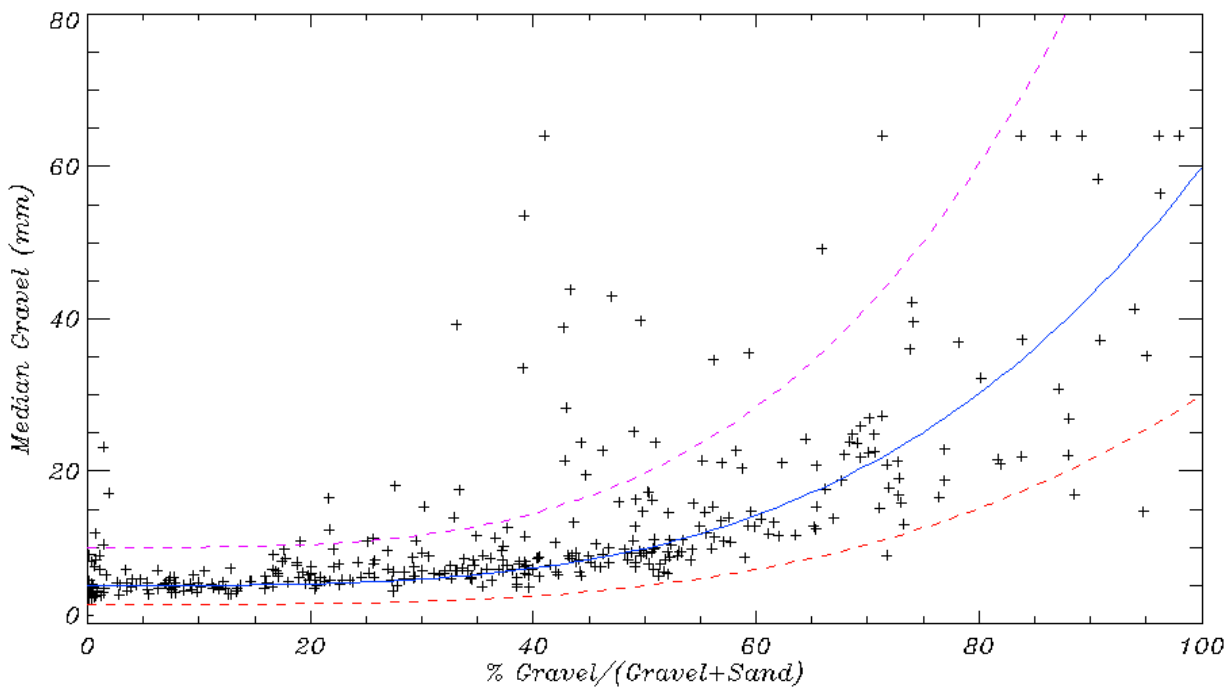

Figure 2: Correlation between median gravel diameter and percentage of gravel. The central line is a best fit curve used to predict median gravel size. Enveloping curves on either side are twice and half the median value. 


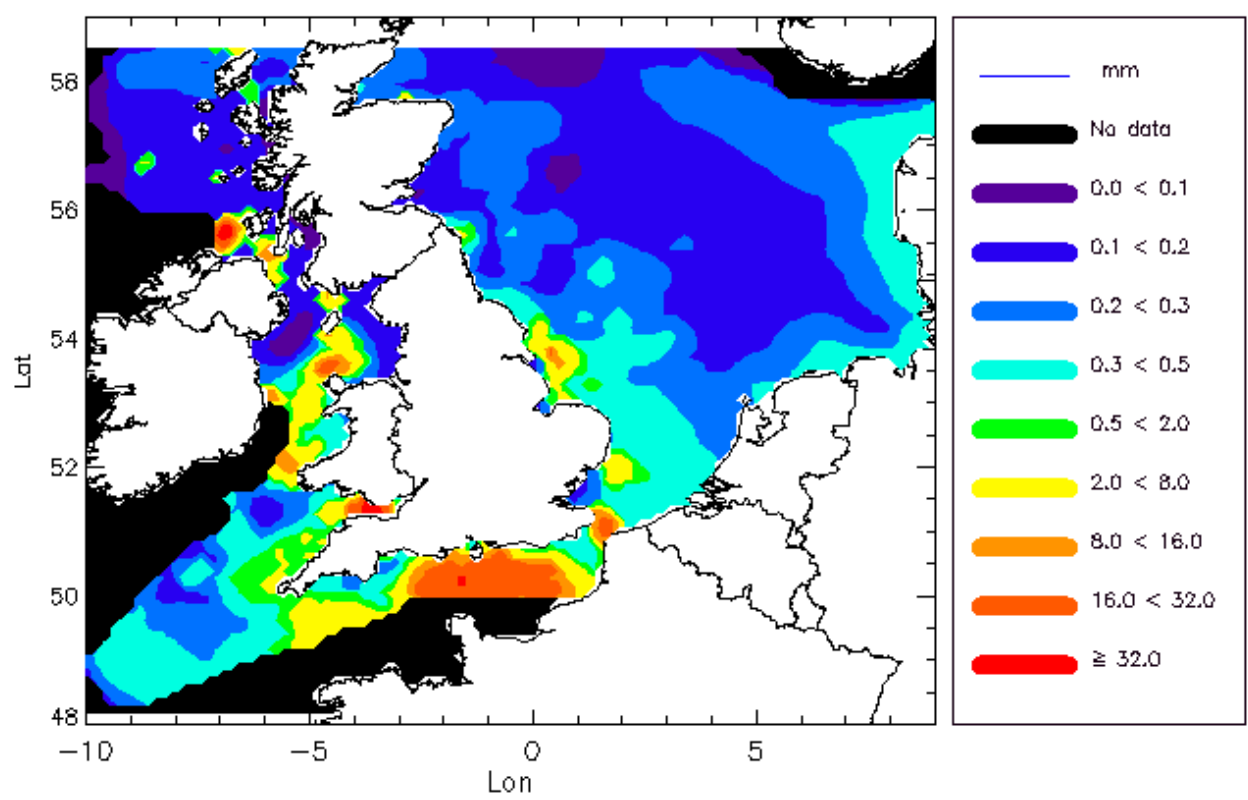

Figure 3: Median grain size distribution (mm). Data sources were from: i) North Sea benthos Survey, ii) The British Geological Survey, and iii) Cefas. In gravel regions sizes are partly inferred from Equation 7.

\subsection{Disturbance prediction}

Disturbance was taken to mean physical movement of the surface layers of the seabed sediment. The intensity of natural disturbance was quantified by estimating the number of days in a year the bed was disturbed by tides and waves. Central to the approach adopted was the definition of a disturbance 'event' associated with a fixed time window. The time window was taken to be one day and multiple disturbances within one day counted as a single disturbance 'event'. The period of a day was chosen to reflect approximately the duration of a typical significant wind event or 'storm' so that this would count as a single disturbance event. Clearly this is not exact and a different choice of time window would change to some variation in the predicted disturbance frequency. For each simulated day, a prediction was made at each grid location of whether bed disturbance had occurred and (for sand) the maximum disturbance depth over that day. A cumulative record was kept to give the 'disturbance frequency' - defined as the number of days in a year the bed was predicted to be disturbed (to a given depth) at each grid point. Note that the disturbance considered in this study is not just that associated with wind-driven events but may be due to tidal currents. The procedure adopted for sand, mud and gravel beds is described later in the appropriate sections.

Many of the relations used in this study to predict bed disturbance were derived from best fits to highly scattered laboratory or field data. An important aspect of the work was an attempt to quantify uncertainty in the predicted annual disturbance frequency by undertaking a Monte Carlo simulation. Let $\mathrm{Y}(\mathbf{u}, \mathbf{s})$, be some deterministic prediction depending on hydrodynamic forcing $\mathbf{u}$ and bed characteristics, $\boldsymbol{s}$. In our case Y will represent either a stress threshold disturbance above which disturbance is assumed to occur or a prediction of disturbance depth. Assuming Y was derived from a fit to scattered data, a set of runs was undertaken where in each run, Y was scaled by a multiplier $\xi\left(\xi_{1} \leq \xi \leq \xi_{2}\right.$ ) taken from a probability distribution with Cumulative Distribution Function (CDF) chosen (subjectively) to represent the scatter in the experimental data. It is emphasised that the uncertainty and associated probabilities that we later calculate arises from out lack of ability to predict ripple formation it is not implied that ripple formation is itself a stochastic process.

Once fixed, each value of the parameter $\xi$ gives rise to a particular value of annual disturbance frequency $\mathrm{N}(\xi)$ at a given location. The way that $\xi$ enters the formulation (described later) was designed so that disturbance frequency is a non-increasing or non-decreasing function of $\xi$. This allows a simple way of ascribing a probability that the disturbance frequency equals or exceeds a given value since, in the case where $\mathrm{N}$ is a non-increasing function of $\xi, \operatorname{Pr}\left(\mathrm{N} \geq \mathrm{N}^{*}\right)=\operatorname{Pr}\left(\xi \leq \xi^{*}\right)=\mathrm{F}\left(\xi^{*}\right)$ where $\mathrm{F}$ is the chosen CDF. For the non-decreasing case this becomes $\operatorname{Pr}\left(\mathrm{N} \geq \mathrm{N}^{*}\right)=\operatorname{Pr}\left(\xi>\xi^{*}\right)=1-\mathrm{F}\left(\xi^{*}\right)$. An ensemble of calculations was performed selecting $\xi$ at the $10,20,30 \ldots 100$ percentiles of $F(\xi)$ and then inverting the $N(\xi)$ relationship to obtain the probability that the number of days of disturbance over a year exceeds a given value, that is, $\operatorname{Pr}\left(\mathrm{N} \geq \mathrm{N}^{*}\right)$ for $\mathrm{N}^{*}=0,1,2 \ldots .365$. In practice this inversion can 
be problematic when $\mathrm{N}$ takes on only discrete integer values since a range of values of $\xi$ can give the same $\mathrm{N}$. In this case it is the maximum/minimum value of the range that needs to be taken in the non-decreasing/nonincreasing case respectively. As a general comment, it is noted that only certain specific sources of uncertainty were included in the analysis. The effect of uncertainty in the modelled wave and current inputs for example was not quantified, although in principle this could be done.

\subsubsection{Sand}

For sandy substrates natural disturbance of the bed is indicated by the occurrence of bedforms resulting from the movement of sediment by hydrodynamic processes. Bedforms occur over a large range of length scales, from ripples with wavelengths of a few centimetres to sand banks many kilometres in length. It was deemed that the most appropriate scale of bedform to compare with anthropogenic impacts were ripples (height $<5-10 \mathrm{~cm}$ ) and small-scale dunes or megaripples $(10 \mathrm{~cm}<$ height $<50 \mathrm{~cm})$ on the basis that disturbance depths $(1-10 \mathrm{~cm})$ and timescales (changes over minutes to hours) associated with these bedforms were closest to the relatively sudden disturbance events associated with a anthropogenic disturbance types such as beam trawling and aggregate extraction. Depth of disturbance was taken as half the predicted bedform height on the assumption that the bedform is equally distributed above and below the level of an undisturbed bed. It is noted that the net erosion and deposition of sediment in the North Sea appears to be relatively small, amounting to annual changes of a few millimetres per year (Van der Molen, 2002) and is insignificant compared to the reworking in place of bed sediments associated with bedforms. However this may underestimate the effect of erosion and deposition on steep inshore banks, as transport down relatively steep sided banks could be quite large even over a tidal period.

Although some observations have been made of bedform generation under interacting waves and currents (e.g. Li \& Amos, 1998) no attempt was made to account for this and current and wave generated bedforms were assumed to exist independently with the maximum was taken as the disturbance depth.

Based on fits to laboratory and/or field data, a number of workers have proposed empirical formulae for predicting equilibrium bedform heights as a function of hydrodynamic conditions. In most cases the data show rather a large scatter around the fitted curves. To take account of this uncertainty in predicting bedform heights, the value of $\hat{\eta}$ was calculated from

Equation $8 \quad \hat{\eta}_{b}=\varepsilon_{b} \bar{\eta}_{b}$

where $\bar{\eta}_{b}$ is a deterministic height prediction for a possible bedform type (ripple, megaripple, large wave ripple) and $\varepsilon_{b}$ is a random scaling parameter to account for the uncertainty in predicting that bedform height. The probability distributions chosen for $\varepsilon_{b}$ are discussed later.

Bedforms were not assumed to be in instantaneous equilibrium with hydrodynamic forcing. Instead, if $\hat{\eta}_{b}$ is the predicted equilibrium height for a given bedform type, the dynamic heights $\eta_{b}(t)$ were assumed to evolve independently via a first order rate equation of the form

Equation $9 d \eta_{b} / d t=\alpha\left(\hat{\eta}_{b}-\eta\right)$

where $\alpha=1 / \tilde{T}$ and the equilibrium timescale $\tilde{T}$ is a specified relaxation rate for a given bedform type, dependent (in theory) on hydrodynamic conditions. Information on time scales for bedform adjustment to changes in hydrodynamic forcing have been reported by Smith \& Sleath (2005), Soulsby \& Whitehouse (2005) and Doucette $\&$ O'Donoghue (2006) and were used as guide to specifying $\alpha$.

In the calculations, $1 \mathrm{~cm}$ depth bins are defined and bedform heights were halved and rounded to the nearest depth bin to obtain the disturbance depth. At a given location, the maximum over the disturbance window of a day and over all bedform types was taken as the disturbance depth. 


\section{Current generated bedforms}

For the purpose of bedform generation, tidal flows were assumed to change on a slow enough time scale to be considered as steady currents. For current generated bedforms there appears to be some consensus (e.g., Southard \& Boguchwal, 1990) that the types of small-scale bedforms is broadly in line with that shown in Figure 4. With increasing Shields number, the bed moves from a state of no motion to a ripple regime followed by a transition to dune/megaripple bedforms and finally a flat upper plane bed associated with high Shields number and sheet flow conditions. For the ripple regime, equilibrium ripple dimensions appear to depend on the grain size only (Baas, 1993). In this study predictions of current ripple height used a form derived by Soulsby \& Whitehouse (2005)

Equation $10 \quad \bar{\eta}_{c} / D_{50}=202 D_{*}^{-0.55}, \quad 1.2<D_{*}<14$

where $D_{*}$ is the non-dimensional grain size ( Equation 6). The equilibrium timescale for current ripples in Equation (9) was taken as $\tilde{T}=\tilde{T}_{C}=1$ hour. This predictor was assumed deterministic i.e. $\varepsilon_{b}$ in Equation 8 was

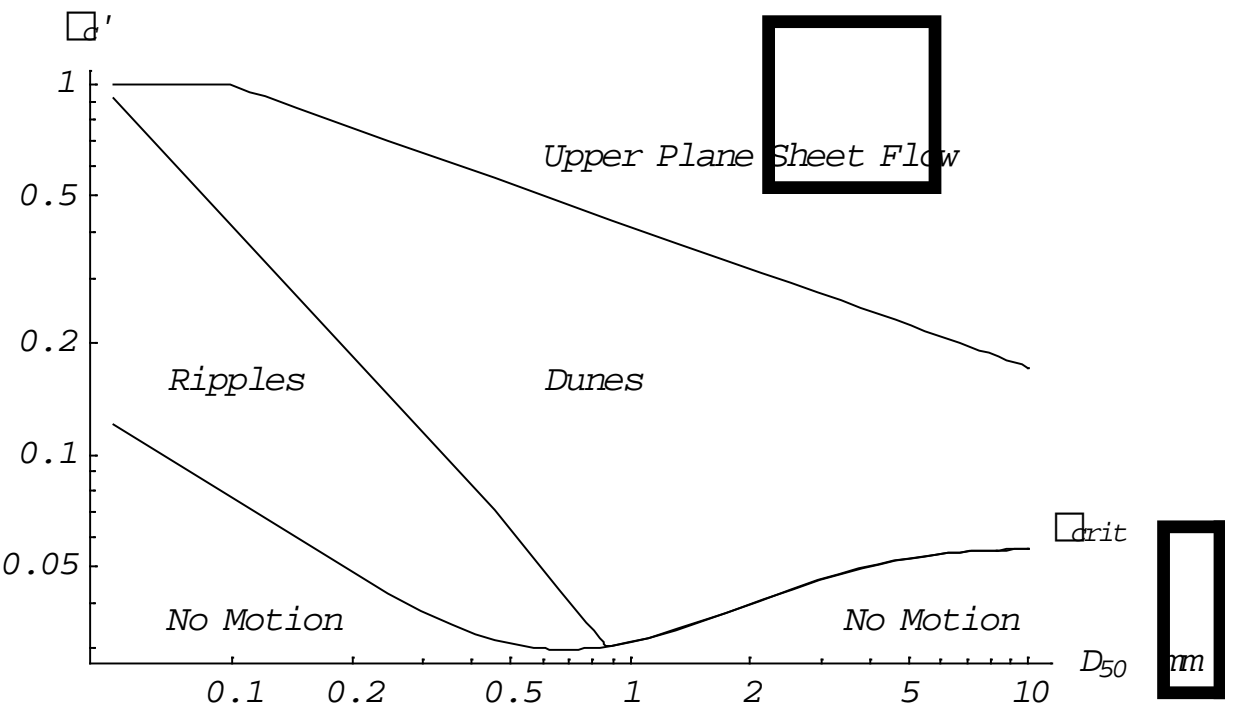

Figure 4: Tentative regime boundaries for small-scale current generated bedforms expressed in terms of the median grain diameter and current skin friction Shields parameter $\theta_{c}^{\prime}$.

There is some debate about the nature of tide generated bedforms of intermediate size (denoted 'dunes' in Figure 4) and their relationship to megaripples (see e.g. Ashley 1990, Bartholdy et al. ,2005). This is explored further in the discussion section but for now dunes and megaripples are regarded as the same bedform and the names used interchangeably. For our purposes megaripples/dunes are regarded as intermediate in size between ripples and sand waves with typical heights of $10 \mathrm{~cm}$ to $100 \mathrm{~cm}$ that migrate and develop over timescales within a six hour tidal flood or ebb period. Two possible formulae for predicting the onset of these bedforms are considered in this study and the difference in the predicted distributions is described in the results section. Based on a synthesis of existing flume data Soulsby and Whitehouse (2005) propose

$$
\text { Equation } 11 \theta_{\text {dune }}^{\prime}=\max \left\{0.916,1.66 D_{*}^{-1.33}\right\}
$$

as marking the point of ripple 'washout' and the start of dune formation and this is the relationship shown in Figure 4. An earlier proposal by Johnson et al. (1981) used flume data to propose a transition from ripples to larger bedforms (that they termed 'small sand waves') based on the total Shields number $\theta_{\text {dune }}$ and grain Reynolds number $\operatorname{Re}=D_{50} u_{*} / v, \quad u_{*}=\sqrt{\tau / \rho}$. Their graphical relationship (Johnson et al. 1981, figure 2) can be expressed algebraically as 
. Note that Johnson et al. (1981) use the total stress in their analysis so that $\tau=$ form drag + skin-friction. We calculated the total stress from (1) with bed roughness $k_{s}=2.5 D_{50}+\eta_{r}$ where $\eta_{r}$ is the calculated current ripple height. When applied to the North Sea, Johnson et al. (1981) found good agreement with observed distributions of sand waves. They suggested there should be a seasonal effect on small sand wave distributions entering via the temperature dependence of the kinematic viscosity $v$. This was included in our calculations using a climatological seasonal water temperature curve. A depth average value was used assuming dune formation occurs in regions with relatively high currents and therefore well mixed. Both relationships were used in this study and the outcomes discussed in the results section.

Where megaripples/dunes were predicted, bedform height was calculated using the field observations based relationship of Bartholdy et al. (2005)

$$
\text { Equation } 13 \bar{\eta}_{M}=1.5 \theta_{c}^{\prime}\left(1.1-\theta_{c}^{\prime}\right)
$$

The corresponding equilibrium time for Equation (9) is speculative and the assumption $\tilde{T}_{=10} \tilde{T}_{c}\left(\tilde{T}_{c}=1\right.$ hour $)$ was made. The height prediction was assumed to be deterministic i.e. $\varepsilon$ in Equation 8 was fixed equal to 1 for this bedform type.

The transition to a flat upper plane bed under sheet flow conditions was assumed to occur when the skin friction wave-current shields number $\theta_{w c}^{\prime} \geq \theta_{\text {sheet }}^{\prime}$ where, for a wave spectrum, the near-bed orbital velocity based on the equivalent monochromatic wave was used to calculate $\theta^{\prime}{ }_{w c}$. The threshold value

$$
\text { Equation } 14 \theta_{\text {sheet }}^{\prime}=\operatorname{Min}\left\{1.0,1.4 D_{*}^{-0.38}\right\}
$$

is a non-dimensional version of the relationship proposed by Li \& Amos (1999) based on previous work and their own field observations of combined wave-current flows. When sheet flow conditions are predicted wave and current bedform heights are set to zero and the dynamic bedform heights decay to zero via Equation 9.

\section{Wave generated bedforms}

For wave generated bedforms, observational evidence (e.g., O’Donoghue et al., 2006; Pedocchi \& Garcia, 2009 and others) indicates a pattern that is broadly analogous to the case for currents. A well-defined ripple regime is followed by a transition to larger scale bedforms at higher wave stress (Swift et al., 1983; Li \& Amos, 1999) and finally sheet-flow at high Shields number (Figure 5). In the ripple regime 0'Donoghue et al. (2006) suggest (based on data from a number of previous studies) that 2D wave ripples form only in coarser sand ( $\left.\mathrm{D}_{50} \sim>0.3 \mathrm{~mm}\right)$.

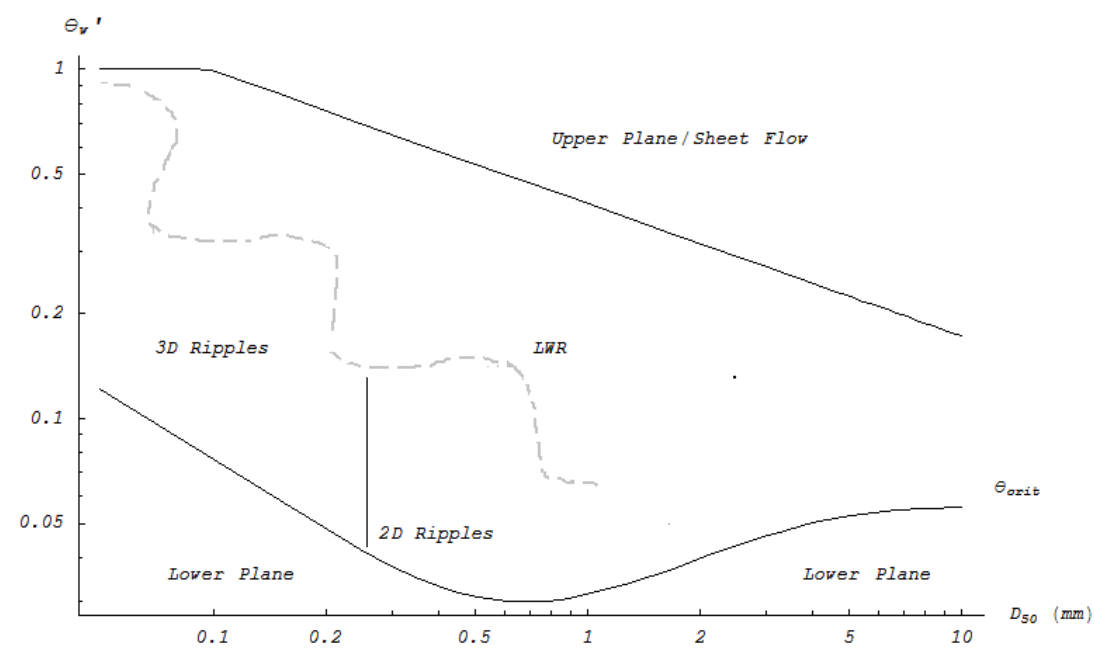


Figure 5: Tentative regime boundaries for small scale wave generated bedforms expressed in terms of the median grain diameter and wave skin friction Shields parameter $\theta_{w}^{!}$. The criteria used for transition to Large Wave Ripples (LWR) was based on the mobility number and cannot be translated uniquely into a Shields value and is represented schematically by a wavy dashed line.

Wave ripples were assumed to form when the wave stress based on the EMW exceeded the threshold for movement given by the standard Shields curve. A large number of predictors of equilibrium ripple height and wavelength have been proposed. Most can be written in the general form $\bar{\eta}_{w}=f(\chi) A$; where $\hat{\eta}_{w}$ is ripple height, is some measure of the near-bed orbital excursion, $f$ is a non-dimensional function and $\chi$ is a non-dimensional measure of wave strength. The ripple predictors of O'Donoghue et al. (2006) and Soulsby \& Whitehouse (2005) were used in this study. These were selected on the basis that: 1) they were developed taking advantage of data and insights from a previous work; 2) they were calibrated using the large dataset of observations now available; 3) they use independent variables that are relatively unambiguous and easy to measure; 4) there is a recommendation of how they should be applied in the case of a wave spectrum. Note that both of the formulae are based on log-log transformed fits to often very scattered data. O'Donoghue et al. (2006) calculate the equilibrium wave ripple height as $\bar{\eta}_{w}=A_{w} \times \max \left(\eta_{O D L}, 0.0\right)$

$$
\text { Equation } 15 \quad \eta_{O D L}=m\left(0.275-0.22 \Psi^{0.42}\right), \quad \Psi<190
$$

where

$$
\text { Equation } 16 \quad \Psi \equiv U_{10}^{2} /(s-1) g D_{50}
$$

is the mobility number based on the average wave orbital velocity taken over the highest tenth of waves in the spectrum $\left(\mathrm{U}_{10}\right)$. The coefficient $\mathrm{m}=1.0$ and 0.55 for $2 \mathrm{D}$ and $3 \mathrm{D}$ ripples respectively where $3 \mathrm{D}$ ripples are assumed to form for $D_{50}<0.22 \mathrm{~mm}$ and 2D ripples for $D_{50}>0.3 \mathrm{~mm}$ with a linear transition in assumed at intermediate grain sizes. The Soulsby and Whitehouse (2005) formulae has $\bar{\eta}_{w}=A_{10} \times \max \left(\eta_{S w}, 0.0\right)$

Equation $17 \eta_{S W}=0.15\left\{1.0-\operatorname{Exp}\left[-(5000 / \Delta)^{3.5}\right]\right\} /\left\{1+0.00187 \Delta\left(1-\operatorname{Exp}\left[-(0.0002 \Delta)^{1.5}\right]\right)\right\}, \quad \Delta<6000$

with $\Delta \equiv A_{10} / D_{50}$ where $\mathrm{A}_{10}$ is given by Equation 3 but with $U_{w}$ replaced by $U_{10}$.

The corresponding wave ripple equilibrium timescale for Equation 9 was taken as $\widetilde{T}=\widetilde{T}_{w}=1$ hour. The relatively poor performance of ripple predictors and large scatter in the data is explored further in the discussion section. In this study the uncertainty is partly accounted for by undertaking calculations using two ripple height formulations. Beyond the ripple regime, the formation of larger scale, often rounded, bed features under more energetic wave conditions has been recorded both in field observations (Amos, Li \& Choung, 1996; Li \& Amos, 1999) and laboratory experiments (e.g. O’Donoghue et al., 2006; Pedocchi \& Garcia, 2009). Following Li \& Amos, (1999) the larger wave generated bedforms are termed 'Large Wave Ripples' (LWR). The transition between ripples and LWR is rather speculative and the criterion of Donohue et al. (2006) was used. Thus 'washout' of wave ripples and/or a transition to larger bedforms is assumed to occur when

Equation $18 \Psi>190$

. Based on Li \& Amos (1999) and data reported in Pedocchi \& Garcia (2009), who also observed rounded bedforms under their largest waves, a tentative equilibrium LWR height predictor was applied:

$$
\text { Equation } 19 \bar{\eta}_{l w r}=0.1 A_{w}
$$

where the wave excursion amplitude $A_{w}$ was calculated from the equivalent monochromatic wave orbital velocity and the zero crossing period at the bed. When used in Equation 9 the adjustment timescale was set at $\widetilde{T}=\widetilde{T}_{L W R}=3$ hours.

Finally in this section, the details of the uncertainty analysis for sand beds are given. Current ripples were found to be small and confined to the top $1 \mathrm{~cm}$ so an uncertainty analysis was deemed over elaborate and was not undertaken. The megaripple predictor (Equation 13 ) is based on a limited set of field observations so that an assessment of the uncertainty in this relationship could not be made. Thus, for current generated bedforms (ripples, mega ripples and/or dunes) a deterministic depth prediction was assumed. For waves the uncertainty is 
represented by the scaling factor $\varepsilon$ multiplying wave bedform height in Equation 8. Studies comparing deterministic ripple predictors with independent experimental and field measurements (e.g. Soulsby \& Whitehouse, 2005; O'Donoghue et al. 2006; Pedocchi \& Garcia, 2009) give in principle an idea of how much variability there is about the best fit curve representing the ripple predictor. Unfortunately it was not possible to obtain the actual data from these large studies and therefore a subjective assessment based on the published plotted data was made. Because the fits to the data are generally on logarithmic scales, an assumption was made that $\log \varepsilon$ was uniformly distributed in the range $\left[\mathrm{A}^{-1}, \mathrm{~A}\right]$ with $\mathrm{A}=1.5$. Values of $\varepsilon$ then formally obey a reciprocal distribution and can be generated from a uniformly distributed variable random $\mathrm{U} \sim \mathrm{U}(0,1)$ via the relation

Equation $20 \varepsilon \sim A^{1-2 Y}$

The same scaling was used for ripples and LWR. Note the resulting Monte Carlo simulations are relative to the choice of a particular ripple predictor for the mean ripple height.

\subsubsection{Gravel}

For gravel beds, 'disturbance' was deemed to have occurred when the wave-current stress exceeded a threshold for gravel movement. This needs to be made more precise when the waves are given as a spectrum since for any given threshold condition, some proportion of the waves in the spectrum will exceed it and some not. Also, there is the uncertainty in the threshold value itself.

We address the first issue by choosing the EMW as the representative measure of wave orbital velocity and simply defining disturbance to have occurred when the wave-current stress calculated using it exceeds the threshold value. It will be accepted that the results on disturbance frequency will depend on the choice of the EMW. Assuming a modified Rayleigh distribution for the wave orbital velocity amplitude at the bed (You, 2009) about $37 \%$ of waves in the spectrum have an orbital velocity amplitude that exceeds that of the EMW. Because it implies a significant fraction of the waves are exceeding the threshold this choice of representative orbital velocity, although arbitrary, is not unreasonable. For a representative wave period, the zero up-crossing period at the bed was chosen. Note that although the same issues occur for sand beds, the effect is not as important as critical thresholds are generally well exceeded. The maximum (over the wave period) wave-current stress (grain related) was calculated from the wave-current interaction model and the resulting stress used to calculate the nondimensional wave-current Shields number $\theta_{w c}^{\prime}$. Disturbance was deemed to occur when this exceeded the critical threshold for movement $\theta_{\text {crit. }}^{\prime}$

In the limit of large sediment sizes appropriate to gravel, the standard Shields curve gives the critical threshold for movement as $\theta_{\text {crit }}^{\prime} \approx 0.055$. Most workers (e.g. Fenton \& Abbott, 1977; Hammond et al 1984; Panagiotopoulos et al., 1994; Buffington \& Montgomery, 1997) conclude that movement of gravel, under steady currents at least, occurs at a lower threshold value than the 'standard' value. This is attributed to protrusion of individual gravel particles above the mean bed level. Experiments by Sleath (1987) and the work of Giménez-Curto et al. (1996) address this issue and suggest modifications to the calculation of hydrodynamic stress for very rough beds. Komar \& Li (1988) address the calculation of threshold condition for non-uniform gravel sediments using a process based approach for beds with multiple particle sizes. Panagiotopoulos et al. (1994) review previous work and also undertook their own measurements under combined wave-current conditions. In their review they find values of critical skin Shields number in the range $0.01 \leq \theta_{\text {crit }}^{\prime} \leq 0.076$ (mainly for steady currents). Their own measurements when plotted on a standard Shields diagram, showed quite a lot of scatter but again suggested quite low values with $\theta_{\text {crit }}^{\prime} \approx 0.02$. However data plotted in Soulsby (1997, figure 20) would suggest that, for wave-dominated flows at least, the standard value $\theta_{\text {crit }}^{\prime}=0.055$ is reasonable, and may even be rather low. Paphitis (2001) plotted data from a number of previous studies and showed a scatter of values both above and below the standard limiting value for large grain sizes. This scatter was attributed partly to differing criteria for deciding when movement took place, and partly to an inherent difficulty in accounting for all factors affecting movement in a single variable (grain size).

Given the uncertainty in the critical threshold Shields number for gravelly sediments, an ensemble of simulations was carried out using a range of values for $\theta_{\text {crit }}^{\prime}$ between the upper and lower limits [0.03, 0.07] given by Paphitis (2001) based on a number of previous studies. Because these data were plotted on a logarithmic scale it was assumed $\log \theta_{\text {crit }}^{\prime}$ was uniformly distributed on the interval $[0.03,0.07]$ so that $\theta_{\text {crit }}^{\prime}$ follows a reciprocal distribution. A more refined approach might make a distinction between wave and current dominated flows but it was decided there was insufficient information to include this at present. A further important source of 
uncertainty is the apparently rather poorly known distribution of gravel sizes on the continental shelf. With a baseline case of median gravel diameter given by the empirical relationship ( Equation 7 ), separate run ensembles were undertaken for values of $D_{50}$ at half and twice this value (shown by the outlying curves around the central one as shown in Figure 2).

No attempt was made to assign a depth of disturbance for gravel substrates. Nevertheless, some workers have noted the existence of marine bedforms in gravel substrates (e.g. Langhorne, Hearthershaw \& Read, 1986; Forbes \& Boyd, 1987) and attempts have been made to relate gravel bedform dimensions to flow conditions in rivers (Dinehart, 1992; Carling et al., 2005) and in shelf seas (Forbes \& Boyd, 1987). Although the latter might allow a disturbance depth to be assigned, it was in the end decided the present state of knowledge in the marine environment would make such an assignment too speculative at present.

\subsubsection{Mud}

Previous studies (Amos et al., 1992; Perigaud, 1984) identify distinct modes of erosion for cohesive muddy sediments. Surface (or 'type I') erosion typically occurs at hydrodynamic stresses below $1 \mathrm{Nm}^{-2}$ stress and usually leads to erosion depths of a millimetre or less. Structural (or 'type II') erosion is associated with breakdown of the bed structure occurs at much higher shear stress $\left(\sim 10 \mathrm{Nm}^{-2}\right)$ and leads to erosion depths more likely to be of biological significance. Thus, for mud beds, 'disturbance' was deemed to have occurred if a type II erosion event was predicted. No attempt was made to assign a depth to this disturbance.

In contrast to the procedure adopted for gravel and sand beds based on some average of the wave spectrum, disturbance over a muddy substrate was related to the occurrence of extreme waves. The probability that at least one wave in a given wave spectrum will exceed the threshold criterion for type II erosion was calculated as follows. For given $U_{c}, T_{z}$ and $\tau_{c r i t}$, the critical value of orbital velocity $\tilde{u}_{\text {orb }}$ satisfying $\tau_{w c}\left(\tilde{u}_{\text {orb }}, U_{c}, T_{z}\right)=\tau_{c r i t}$ was found by numerical inversion. The probability that a wave with orbital velocity greater than $\tilde{u}_{\text {orb }}$ occurs in the time interval T is given by $p_{x}=1-G\left(\tilde{u}_{\text {orb }}\right)^{n_{i}}$ where $n=T / T_{z}$ is an approximation to the number of individual waves in the period T, and $G$ is the CDF of wave orbital velocity amplitude. The later is taken as a modified Raleigh distribution

Equation $21 p_{x}=\operatorname{Pr}\left(u_{o r b}<\tilde{u}_{\text {orb }}\right)=1-\operatorname{Exp}\left[-\frac{1}{2}\left(\tilde{u}_{\text {orb }} / c_{1} u_{r m s}\right)^{2}\right]$

with $c_{1}=0.96$ (You, 2009). The resulting probability is interpreted as the proportion of the area in a given grid cell disturbed over the time interval T, where in this study T was taken as the interval (1 hour) at which the wave spectrum was sampled. At each hour over the disturbance window of one day the cumulative proportion $p^{n}$ of area disturbed at least once was calculated by assuming the extra new area disturbed is the product of the proportion of undisturbed seabed at $p^{n-1}$ multiplied by the probability of disturbance, yielding the relation

Equation $22 p^{0}=0 ; \quad p^{n}=p^{n-1}+\left(1-p^{n-1}\right) p_{x} ; \quad p^{*}=p^{24}, \quad 1 \leq n \leq 24$

To combine disturbed areas calculated from two successive days consider the following example. Suppose the area disturbed in a model grid box at some point in the computation was 0.6 , meaning 0.6 of the area was disturbed once and 0.4 undisturbed. Suppose on the next day the value calculated from Equation 22 was $p^{*}=1.0$. With this result we have 0.6 of the area disturbed twice and 0.4 disturbed once. This is equivalent to adding areas $0.6+1.0$, provided 1.6 is interpreted as meaning " 0.6 of the area was disturbed twice and 0.4 was disturbed once". For $p^{*}<1.0$ such a simple result does not hold and in general the area disturbed must be represented by a probability distribution over all the possible times the bed could have been disturbed. To avoid a complex and over elaborate calculation we assume that the mean of the probability distribution at least can be approximate by the value obtained by adding the consecutive daily values of $p^{*}$. At the end of a year a value of 3.75 (say) for a given grid cell is interpreted as meaning 0.75 of the area was disturbed on 4 days of the year and 0.25 of the area was disturbed on 3 days of the year. This is consistent with the method used for sand and gravel substrate if it is assumed that natural disturbance on sand or gravel substrates affects the entire area so that $\mathrm{p}^{*}$ is either 0 or 1 . It is emphasised that the probabilities above, interpreted in terms of proportion of area disturbed, are distinct from the uncertainty analysis and associated probabilities that we describe next and are the probabilities to which the results section refers.

As for other substrates an uncertainty analysis was undertaken. Limited information on type II erosion exists but previous studies suggest it can occur for hydrodynamic stress exceeding $\tau_{\text {crit }}$ in the range of 5 to $10 \mathrm{Nm}^{-2}$ 
(Perigaud, 1984; Amos et al., 1992). Uncertainty was accounted for by undertaking an ensemble of runs varying the threshold value. The value was assumed to be uniformly distributed on the interval $[5,11] \mathrm{Nm}^{-2} \mathrm{representing}$ a subjective judgement of the uncertainty. The lower end of the range was set at a relatively high value to reflect that it was a significant disturbance event that was sought.

\section{Results}

Results were calculated using meteorological conditions for the year 2008. When averaged over the whole European shelf, wind speed in 2008 was higher than the 2000-2010 decade average (analysis of NOAA data; Kalnay et al. 1996) with a notable enhancement in the English channel region. A plot of the wind anomaly in included in supplementary material. Further work, to be reported later, will consider inter-annual variability. As the resolution of the bathymetric information $(11 \mathrm{~km})$ was not sufficient to reliably resolve wave conditions near the coast where depths shoal rapidly or in narrow channels between land masses, results and discussion will focus mainly on giving a large scale broad assessment for the offshore continental shelf region.

\subsection{Distribution of wave and current stress}

Wave and current stress are key indicators of bed disturbance and the spatial distribution of these quantities is examined first. The skin friction component of current stress is an increasing function of current speed and bed grain size ( Equation 1). Average current speed (Figure 6) and hence current stress will be dominated by the tidal component. Relatively strong tidal currents and hence average current stresses occur in the southern North Sea, English Channel and parts of the Irish Sea. Annual peak current speeds (Figure 7) will be defined by both extreme tides and by the storm driven component. The relative distribution of peak currents is similar to the average apart from the appearance of large peak current speeds along western-facing coasts of Ireland and Denmark (Figure 7) that we tentatively ascribe to storm events. These might lead to transitory occurrence of dune/megaripple bedforms in regions outside those associated with strong tidal flows..

Wave generated bed stress will be determined by the combination of water depth, wave height, and wave period. An indication of the interplay of these factors is given by the spatial distribution of the annual peak of wave excursion at the bed (Equation 3). In the North Sea this quantity shows a fetch related increase from west to east leading to large values along the Danish coast (Figure 8). In general, west facing coastal regions show relatively large wave intensities due the effect of fetch combined with prevailing westerly winds. A strong dependence on bathymetry is also evident due to the exponential decrease of wave orbital velocity with depth. In the North Sea for example, large bed excursions occur over the relatively shallow Dogger Bank at around $4^{\circ} \mathrm{W}, 55^{\circ} \mathrm{N}$.

Wave and current stress were combined using the wave current interaction model and the annual peak value of the grain-related combined wave-current bed stress distribution was calculated (Figure 9). The results show the contribution of tidal bed stress in the Irish Sea and southern bight of the North Sea, the contribution of waves with high stresses in shallow water and along west facing coasts, and the effect of bed roughness, with the high values of wave-current stress associated with the gravel regions in the English Channel. Similar distributions of current, wave and wave current stress have been presented in Neill, Scourse \& Uehara (2010) although for annual averages and fixed bed friction coefficients. The equivalent quantities (using uniform friction coefficients) were calculated with the present model forcing and plots provided in the supplementary information for comparison with Neill et al. (2010). Similar distributions were obtained allowing that the present model used winds from a different year and also contains the wind driven flows and additional tidal constituents.

If the peak wave-current, grain related, stress distribution is normalised with the critical threshold stress (Equation 5) for the underlying bed, then bed movement at some time over the year should occur where this ratio is greater than 1 . The results indicate that some movement of the bed should occur at nearly all locations (Figure 10). The main exceptions are locations in the English Channel and Irish Sea associated with large grain sizes including occurrence of bedrock (Diesing et al., 2009; Coggan \& Diesing, 2011). However, it should be noted that: 1) for gravel regions the grain size and hence bed roughness is estimated rather than measured and so the threshold stress is highly uncertain ; 2) the standard Shields criterion is an average fit through scattered data; 3) for cohesive mud beds, the Shields curve does not apply. The criterion adopted for mud disturbance (type II erosion) occurs at stresses that are typically two orders of magnitudes higher than that for initial disturbance at surface (of type I erosion). 


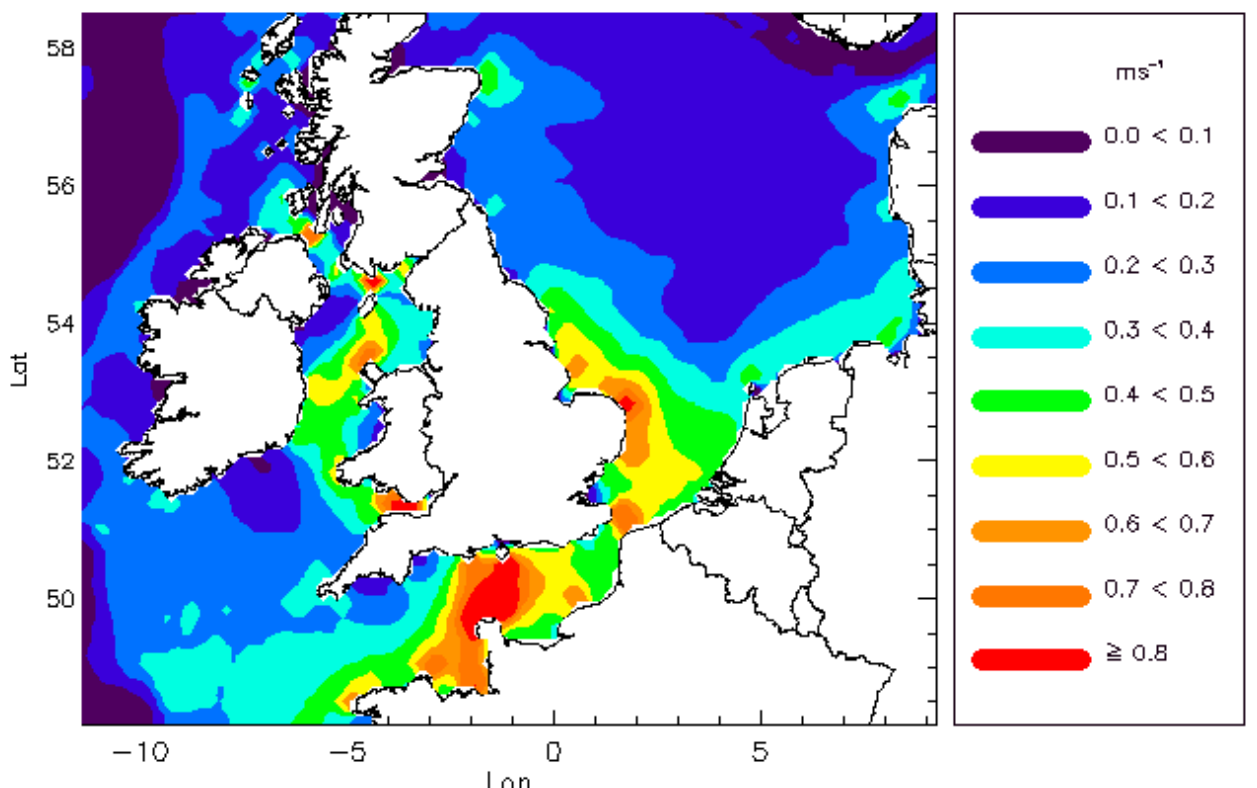

Figure 6: Modelled annual average depth mean current speed (ms $\left.{ }^{1}\right)$ based on meteorological data for 2008.

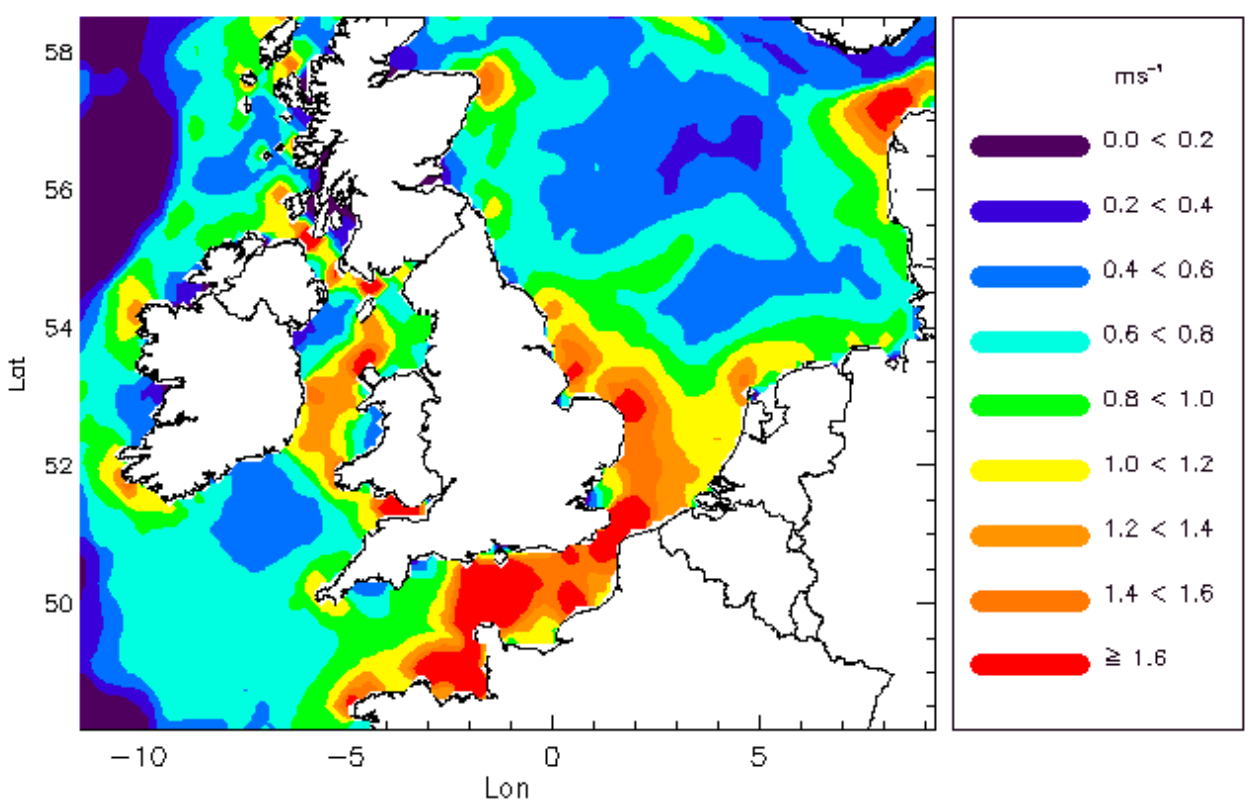

Figure 7: Modelled annual peak depth mean current speed $\left(m s^{1}\right)$ based on meteorological data for 2008. 


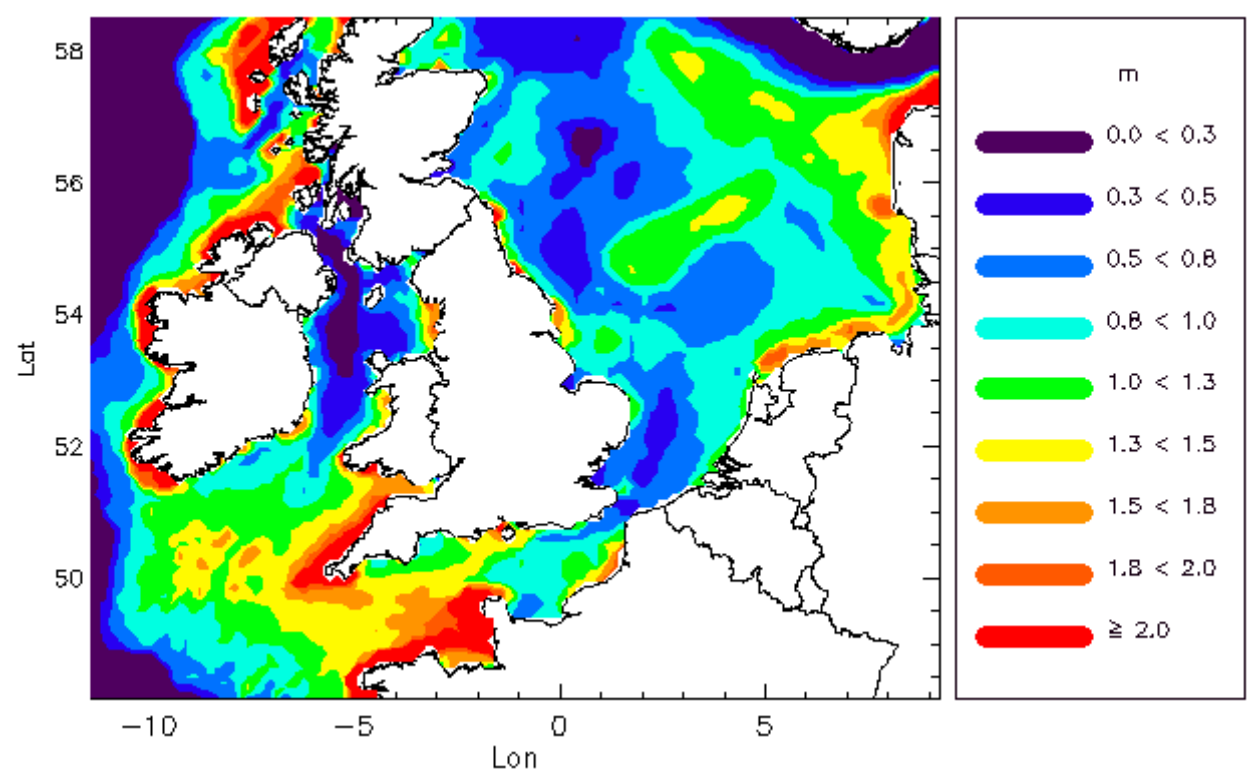

Figure 8: Modelled annual peak bed wave excursion at the bed $A=U_{w} T_{z} / 2 \pi$ based on the equivalent monochromatic wave orbital velocity $U_{w}=\sqrt{2} U_{\text {rms }}$, mean crossing period $T_{z}$ at the bed and meteorological data for 2008.

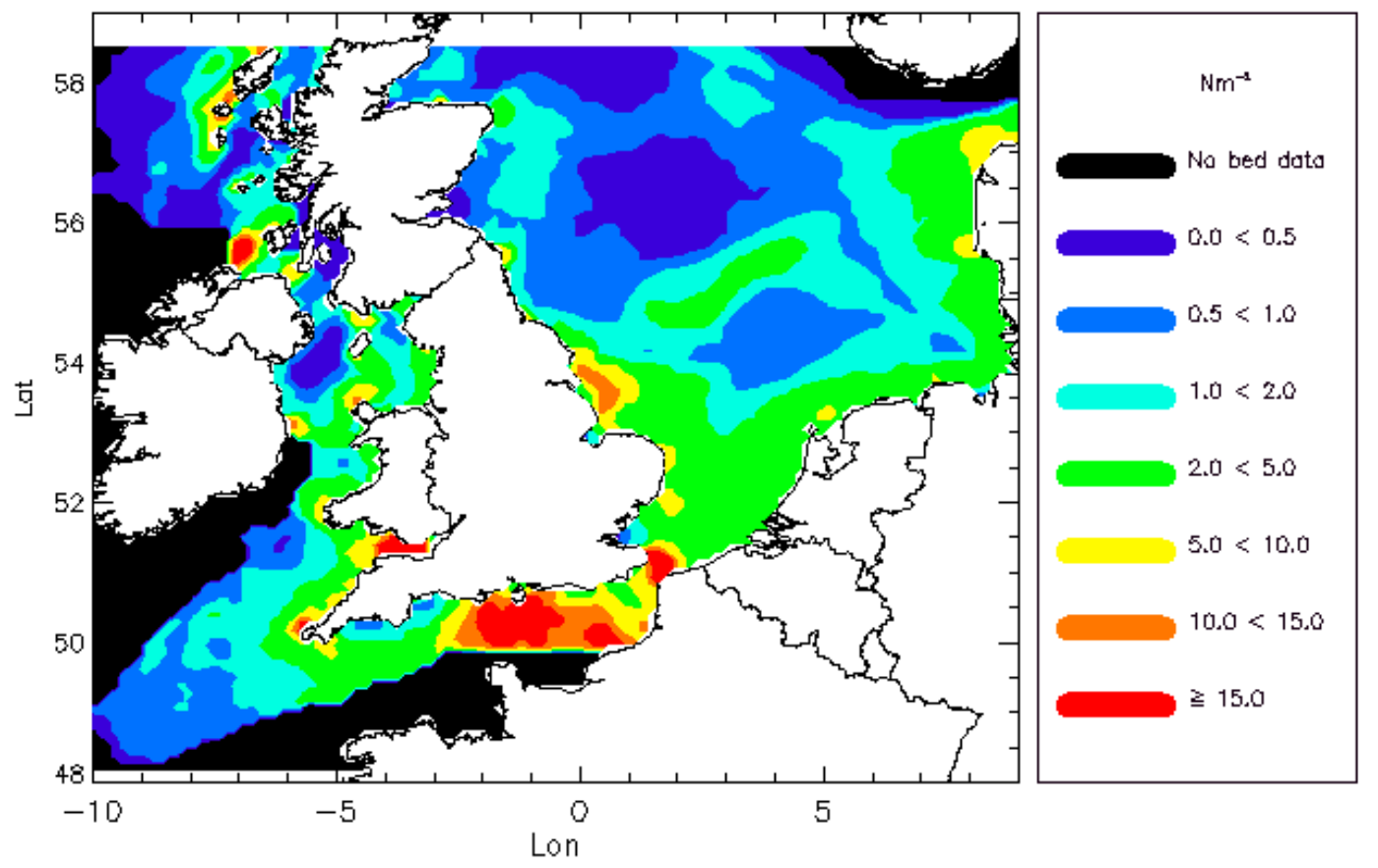

Figure 9: Peak wave-current bed stress based on meteorological data for 2008. Calculated using a wave-current interaction model with spatially varying bed roughness related to median grain size. Note, in gravel areas, median grain size is estimated. Black areas are where bed stress cannot be calculated as no grain size data exists. 


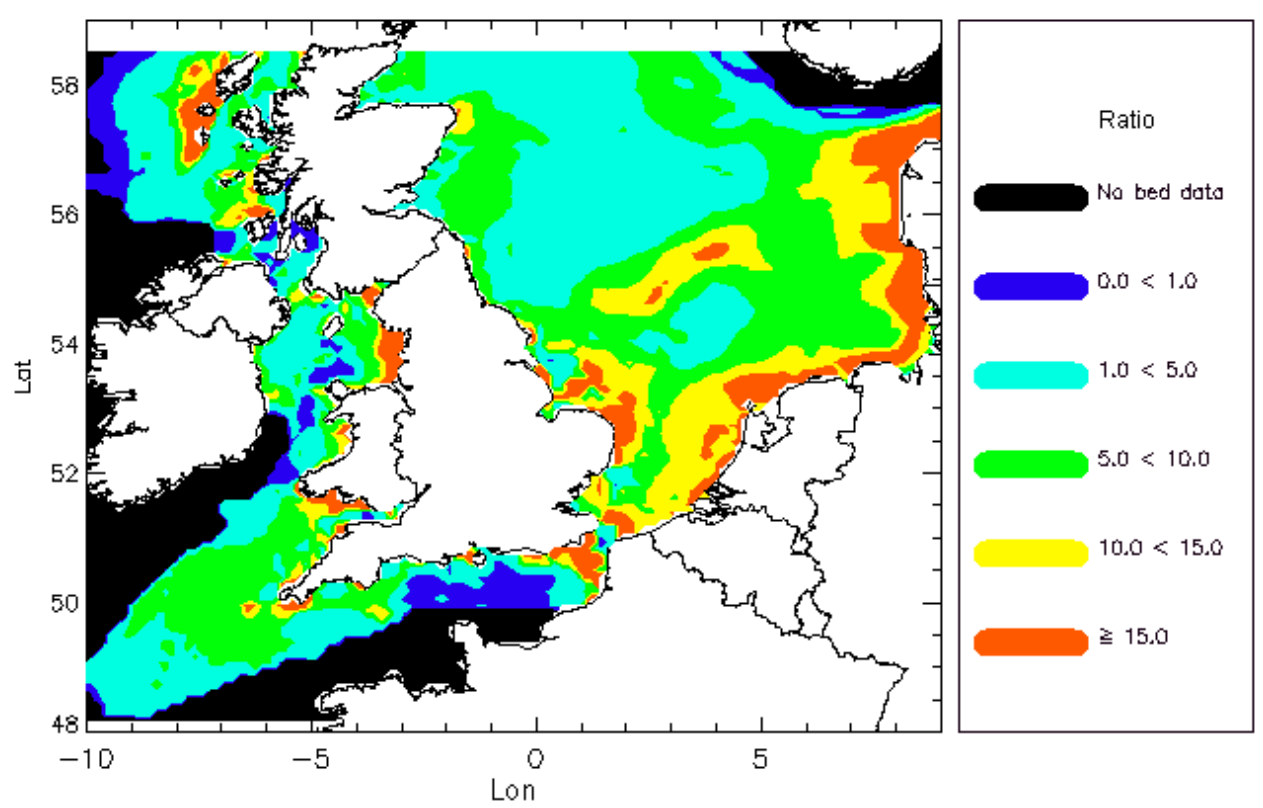

Figure 10: Ratio of maximum annual wave-current stress divided by critical erosion stress based on Shields curve (Equation 5) and median grain size. Note, in gravel areas, median grain size is estimated. Note, for muddy areas the ratio is not meaningful as the Shields threshold does not apply to cohesive sediments.

\subsection{Disturbance over sand substrates}

\subsubsection{Occurrence of bedforms and disturbance depth}

In this study disturbance over sand substrate was associated with the formation of bedforms. Current ripples are assumed to form when the current Shields number (Equation 4) exceeds the standard Shields threshold for the local median grain size (Equation 5). With this criterion, current ripples were predicted at nearly all sand locations at some time in the year. Formation would be expected to be continuous in regions where average tidal velocities regularly exceed the threshold but intermittent otherwise, either due to extreme tides or storm-driven currents. Disturbance depths associated with these bedforms (Figure 11) were predicted to be always less than $2 \mathrm{~cm}$, with $1 \mathrm{~cm}$ being typical.

Megaripple occurrence was predicted in areas of strong tidal currents in the southern North Sea and areas of sand substrate in the English Channel, Celtic Sea and Irish Sea (Figure 12). Transitory formation of these bedforms may occur under storm conditions - for example off the Danish coast. The distribution shown is based on Equation 12 (Johnson et al., 1971). The alternative criterion for dune/megaripple formation (Equation 11; Soulsby and Whitehouse, 2005) yielded a similar, but slightly more restricted region of occurrence. A comparison with maps of observed megaripple occurrence (e.g. BGS 1987) showed good agreement with the modelled distribution around the UK. The number of days per year active megaripple formation occurred was predicted to range from 200 days in areas of strong tides to 2-3 times a year in other locations. Estimates of the megaripple/dune height calculated using Equation 13 (Bartholdy, et al., 2005) generally predicted values in the range $20-40 \mathrm{~cm}$, i.e. disturbance depths of 10-20 cm (Figure 12).

Wave ripples were assumed to form when the wave Shields number, based on the orbital velocity of the equivalent monochromatic wave and zero crossing period at the bed, exceeded the adopted threshold value for the local median grain size. Based on the formula of O'Donoghue et al. (2006) (henceforth ODWR), annual maximum wave ripple disturbance depths of $3 \mathrm{~cm}$ or greater were predicted off the English east coast, in the English Channel and in regions off the Danish coast (Figure 13). The ripple height predictor of Soulsby \& Whitehouse (2005) (henceforth SW) generally gave values for the disturbance depths (Figure 14) that were around $1 \mathrm{~cm}$ less than the ODWR value. This appears to arise from differences in behaviour of the predictors with respect to wave period and is discussed later. 
LWR were assumed to occur whenever wave conditions exceeded the criterion of O'Donoghue et al. (2006) (Equation 18). Occurrence of this bedform type appeared to be associated principally with regions off west facing coastlines (Figure 15) - including most of the west facing shore of the UK, the German bight, Jutland and the Dogger Bank. At nearly all locations the maximum LWR disturbance depth calculated from Equation 19 exceeded $5 \mathrm{~cm}$. In the North Sea the frequency of occurrence of these bedforms was predicted to be generally less than 20 times per year, but increasing with wave fetch eastward and with the highest frequency occurrence on the Dogger Bank and along the Dutch, German and Danish coasts.

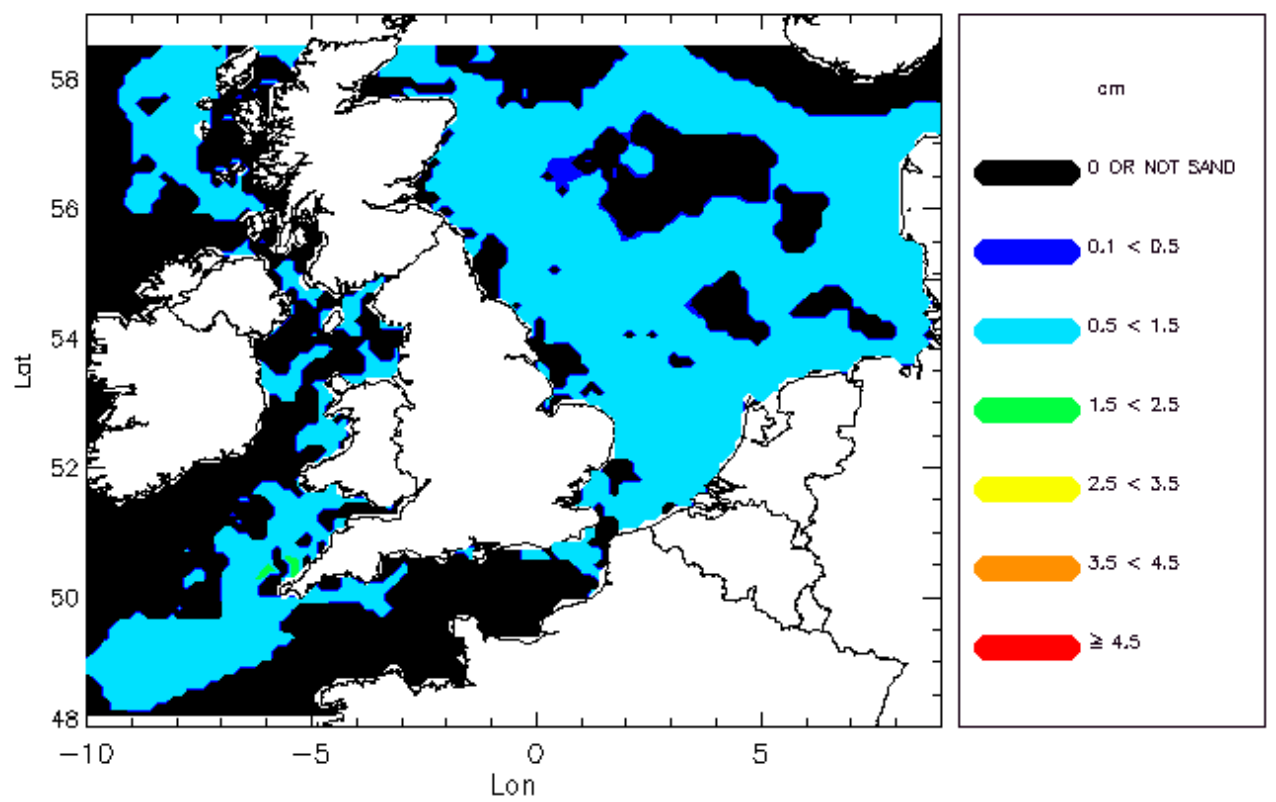

Figure 11: Current ripples, annual maximum predicted disturbance depth (half bedform height, $\mathrm{cm}$ ).

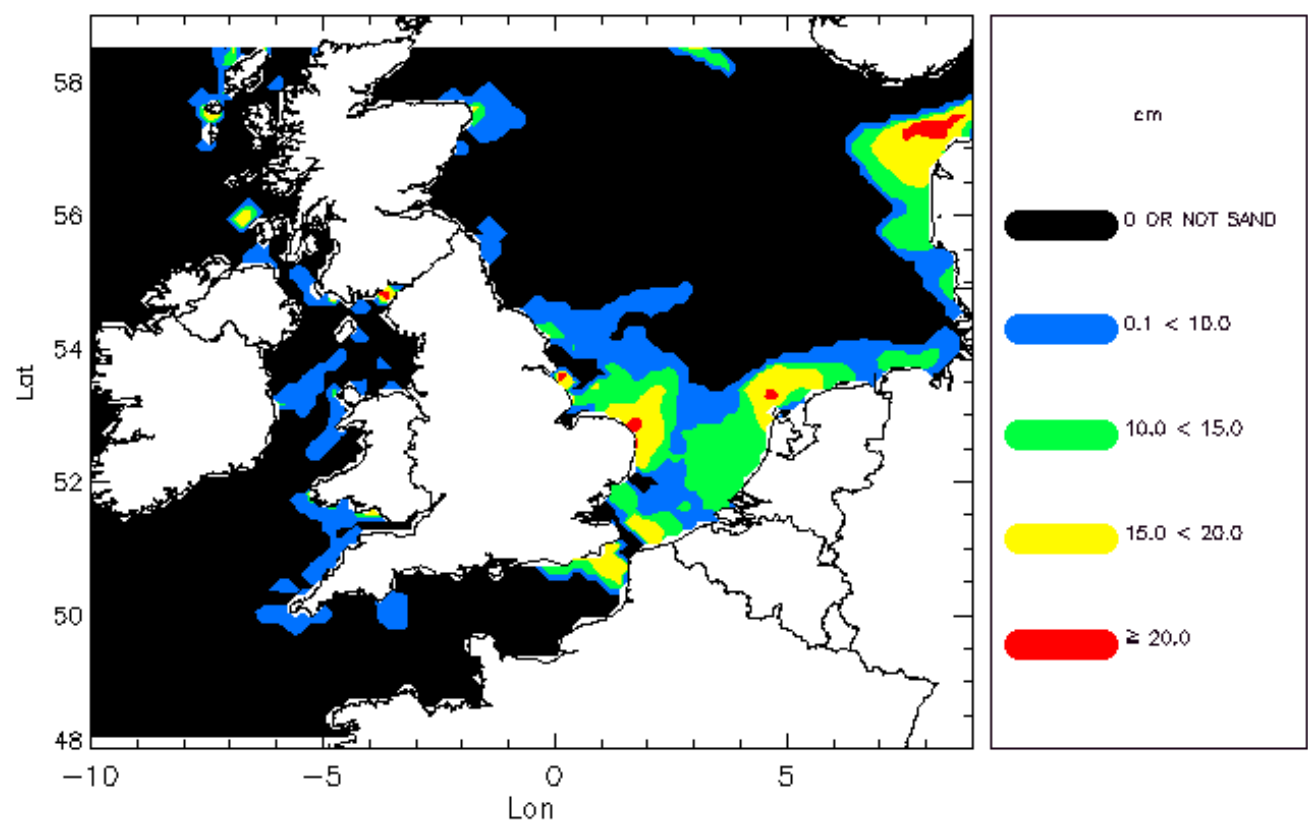

Figure 12: Dunes/megaripples annual maximum disturbance depth (half bedform height, $\mathrm{cm}$ ). 


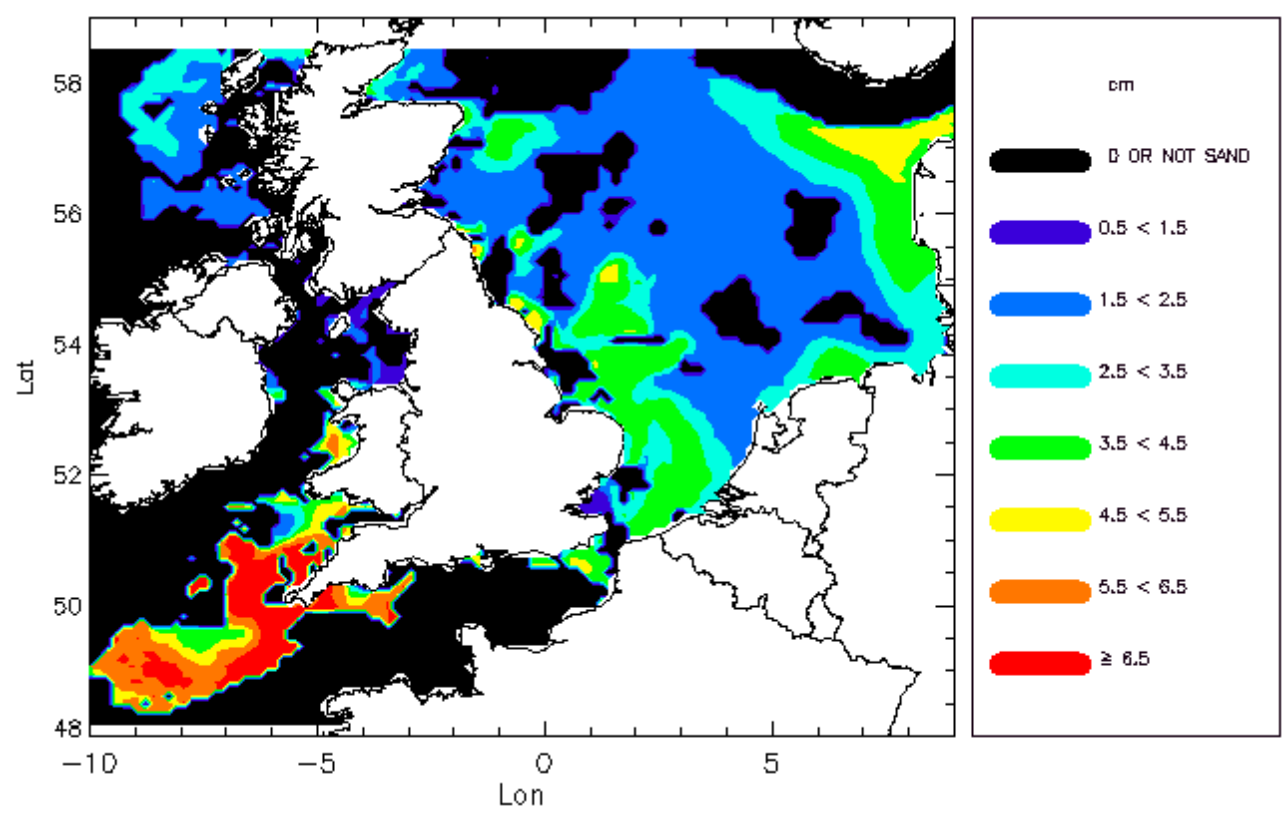

2 Figure 13: Wave ripple predictor of O'Donoghue et al. (2006). Annual maximum disturbance depth (half bedform height, cm)

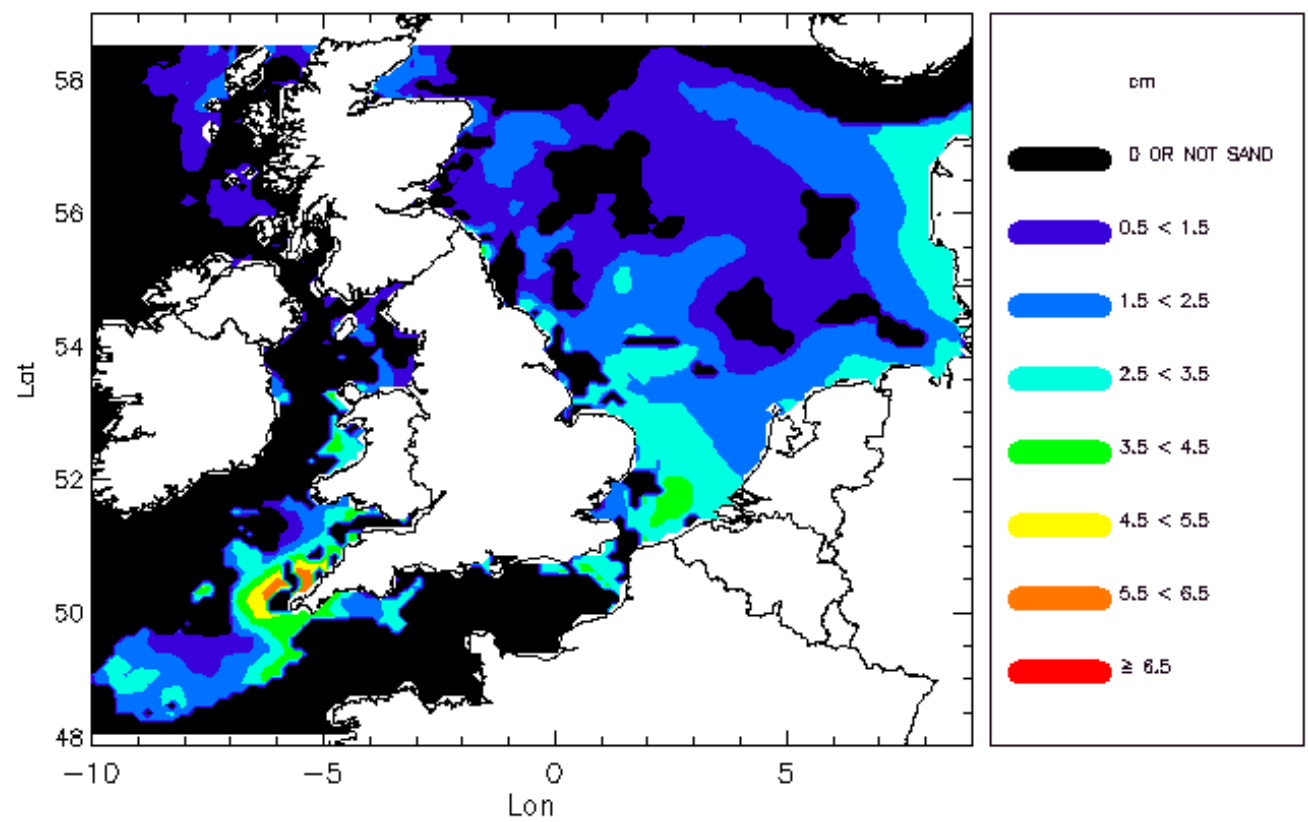

Figure 14: Wave ripple predictor of Soulsby \& Whitehouse (2005). Annual maximum disturbance depth (half bedform height, cm). 


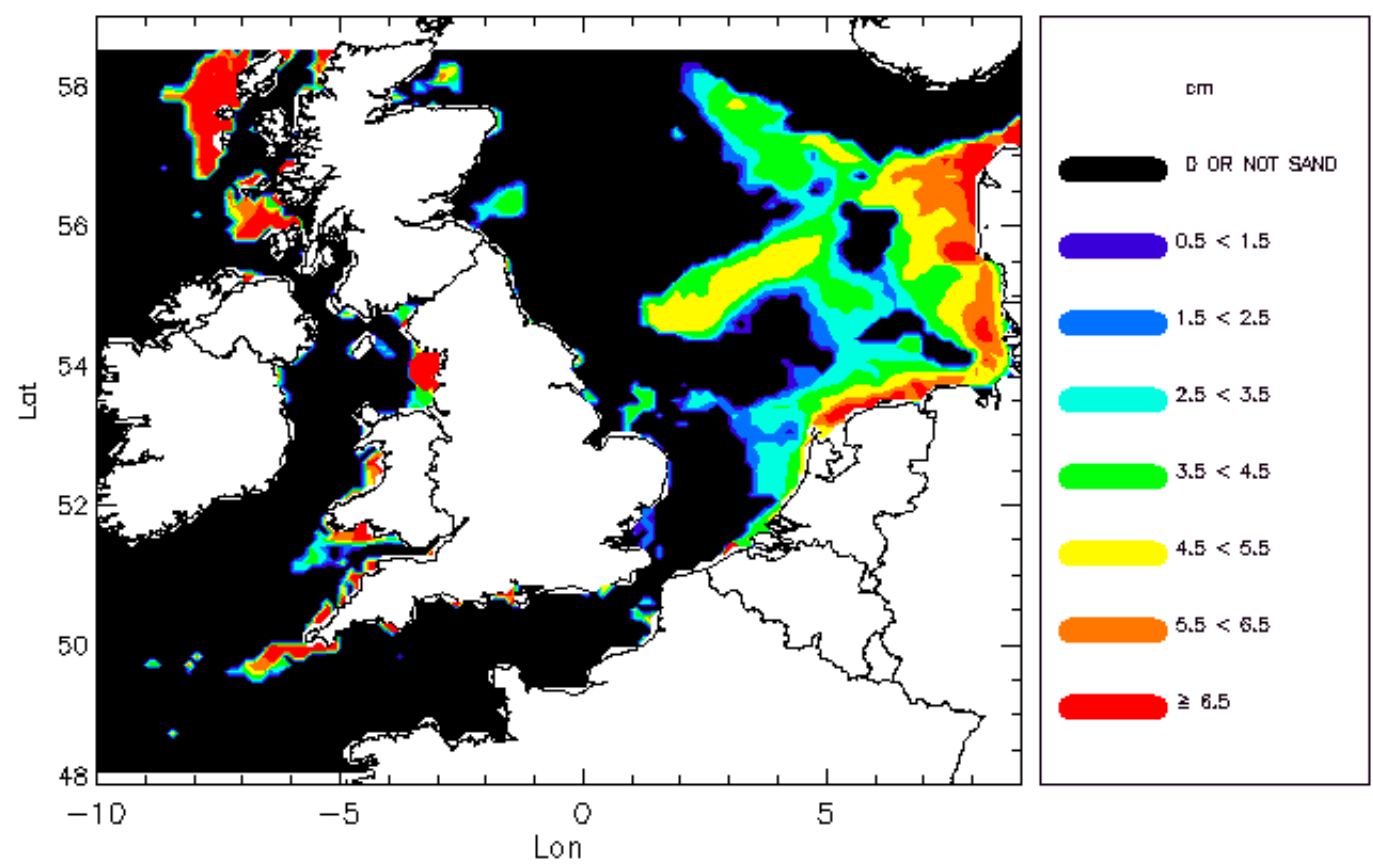

Figure 15: Large Wave Ripples, annual maximum disturbance depth (half bedform height, cm) based on Equation 19.

"Frequency of disturbance depth and uncertainty analysis Next the number of days in a year (i.e. frequency) the bed was disturbed to a given depth by wave and current generated bedforms was calculated, taking account of the uncertainty in wave bedform height prediction represented by the chosen probability distribution for $\varepsilon$ (Equation 8). Dune/Megaripple bedforms were not included on the grounds that they form more slowly than other bedform types considered and are therefore less comparable with anthropogenic disturbances such as trawling. Also megaripples are often observed in patches interspersed with areas free of these bedforms, indicating that they should therefore be treated differently from other bedform types that cover extended areas.
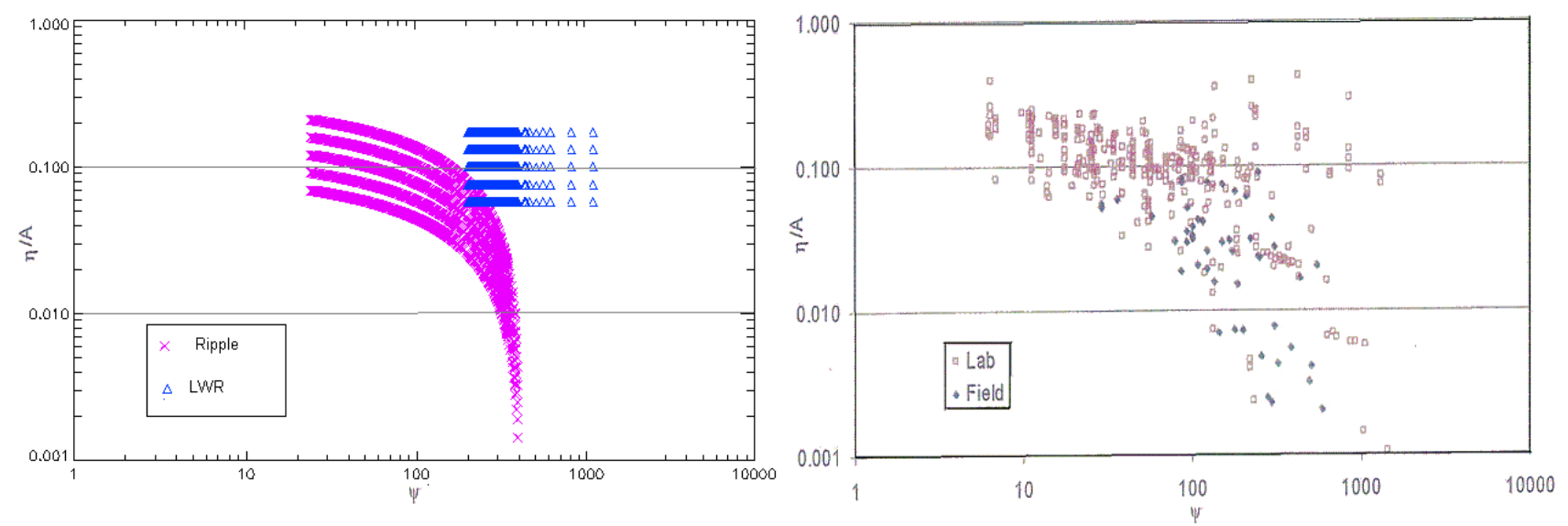

Figure 16: Non-dimensional ripple height versus mobility number. a) Simulated based on a year of input data using the predictor of O'Donoghue et al. (2006) and multiple runs with different scaling factor $\varepsilon$ in the range [0.5, 2]. Each distinct curve represents the range of values obtained from one value of $\varepsilon$. b) Laboratory and field data as collected by Soulsby \& Whitehouse (2005) (reproduced by permission US Office of Naval Research)

To demonstrate that the ensemble runs are correctly reproducing the uncertainty in ripple height prediction, the distribution of modelled wave ripple and LWR heights generated at one location from a year of simulated wave forcing (Fig. 16, left) was compared with measured data (Fig. 16, right) from a large number of existing studies as presented by Soulsby \& Whitehouse (2005). Both sets of data were plotted against a common independent variable wave mobility number $\Psi$ (Equation 16). The general scatter in ripple predictions for mobility number $\Psi$ $<100$ scatter is reproduced by the ensemble runs, although for large values of $\Psi$ the ripple scatter is less 
convincing. Interestingly the results also suggest a possible explanation for the apparent extreme scatter in the observed results when $\Psi>100$. If ripple and LWR bedforms are distinguished as separate bedform types, the model results appear to reproduce the bifurcation in the observed data.

The ODWR predictor was used for the results shown next so that all probabilities are relative to use of this ripple predictor. Model results are presented for disturbance to depths of 3 and $5 \mathrm{~cm}$. These illustrate the differing bedform types that are most relevant in a given depth range. To describe the probability distribution of predicted disturbance from the run ensemble the following three quantities were plotted for a number of disturbance depths: a) $\mathrm{P}_{>0}$, the probability that disturbance occurs to the given depth at least once in the year; b) $N_{50}$, the median value of disturbance frequency at the given depth (days year-1), and c) the difference between upper and lower limits (i.e. the range) of the disturbance frequency. Also useful for interpretation is the range relative to the average $U=$ Range / (Median +1$)$ where the +1 in the denominator avoids problems when the median is zero. Values of $\mathrm{U}<1.0$ indicate that the median gives a reasonable measure of a typical value, while if $U>2.0$, the average has a limited significance as a typical value.

Results for disturbance to depths of $3 \mathrm{~cm}$ (bedform heights $\approx 6 \mathrm{~cm}$ ) suggest that the Dogger Bank, the Dutch, German, Danish coastal region and the west coast of the UK are likely (probability $>0.75$ ) to be subject to wave reworking to this depth (Figure 17a). It is less certain that regions in the central North Sea other than the Dogger Bank are disturbed to this depth (probability $<0.5$ ). The median disturbance frequency (Figure 17b) showed a strong link to water depth and wave fetch, with the highest disturbance frequencies associated with shallow sand banks and western coastal regions. Locations with a high median disturbance frequency tended to have a large range (Figure 17c) but the ratio of range to the median $U$ (not shown) was found to be lowest in regions with high disturbance frequency. Where the median disturbance frequency was low, e.g. in some parts of the northern North Sea, the range can be large relative to the median, even if the absolute range of ensemble predictions may be rather small.

Disturbance to depths of $5 \mathrm{~cm}$ (i.e. bedform heights of $\approx 10 \mathrm{~cm}$ ) was predicted with greater than 0.5 probability only on the Dogger Bank, areas off the Dutch, German and Danish coasts, and exposed west coast regions of the UK (Figure 18a). For the ensemble median, disturbance was predicted to occur on less than 20 days per year at almost all locations and less than 5 in most regions (Figure 18b). For disturbance to $5 \mathrm{~cm}$ the areas of highest median frequency value and greatest range tended to coincide (Figure 18c). However unlike the case for disturbance to $3 \mathrm{~cm}$, the distribution of $U$ tended to give a high uncertainty at locations with significant probability of disturbance and low uncertainty in regions likely to be undisturbed. This is expected from a consideration of how uncertainty will vary with disturbance depth. Highest uncertainty should occur around the maximum depth predicted by a given ripple formula (which appears to be around $5 \mathrm{~cm}$ for the ODDW and LWR formulae) This is because for a shallower depth, all members of the ensemble will predict disturbance, giving high certainty; while in very deep layers all ensemble members will predict little or no disturbance, again giving high certainty. The region off the southwest of the UK was unusual in having a high disturbance probability coupled to low uncertainty (i.e. a high confidence in the predicted disturbance frequency). This was because the predicted mean depth is much larger than $5 \mathrm{~cm}$ (see Figure 13). At $5 \mathrm{~cm}$ the dominant cause of disturbance at most locations was predicted to be Large Wave Ripples. Again the exception was the southwest coast of the UK where 'normal' wave ripples forming in coarse sand under long period waves appear to be the agents. However, this was partly dependent on the choice of the ODDW as wave ripple predictor. The SW formula gave values that were typically only half the ODDW values at this location and did not suggest that this area was unusual.

If current generated megaripples were included in the analysis (Figure 19) then disturbance to $5 \mathrm{~cm}$ and greater was found to be common at most locations where megaripples were predicted (Figure 12) with a high disturbance frequency particularly evident in the tidally dominated southern North Sea. 

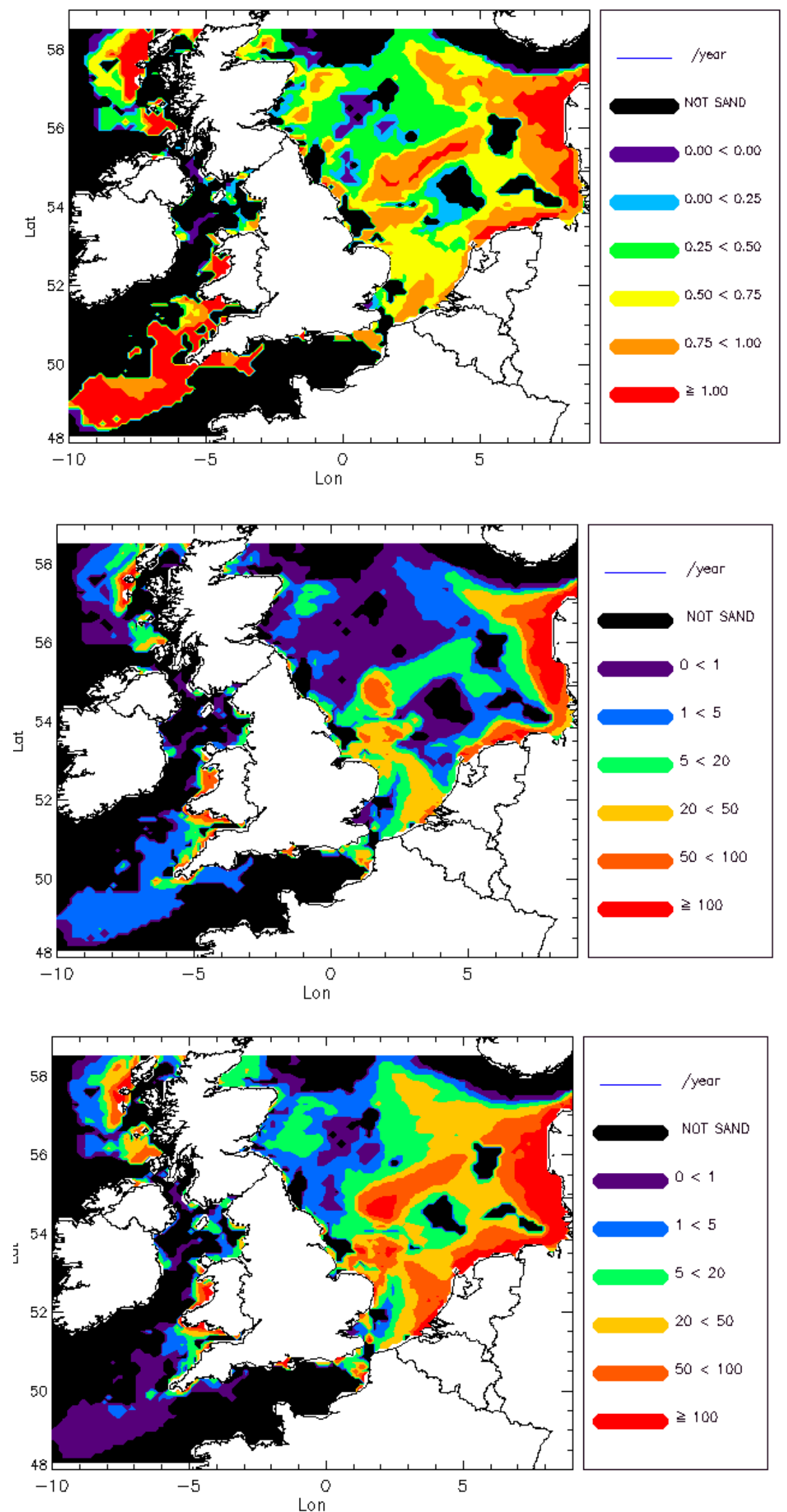

Figure 17: Disturbance at $3 \mathrm{~cm}$ for sand beds: a) Probability that disturbance occurred at least once in year; b) Median disturbance frequency; c) Range of disturbance frequency (Max-Min). 

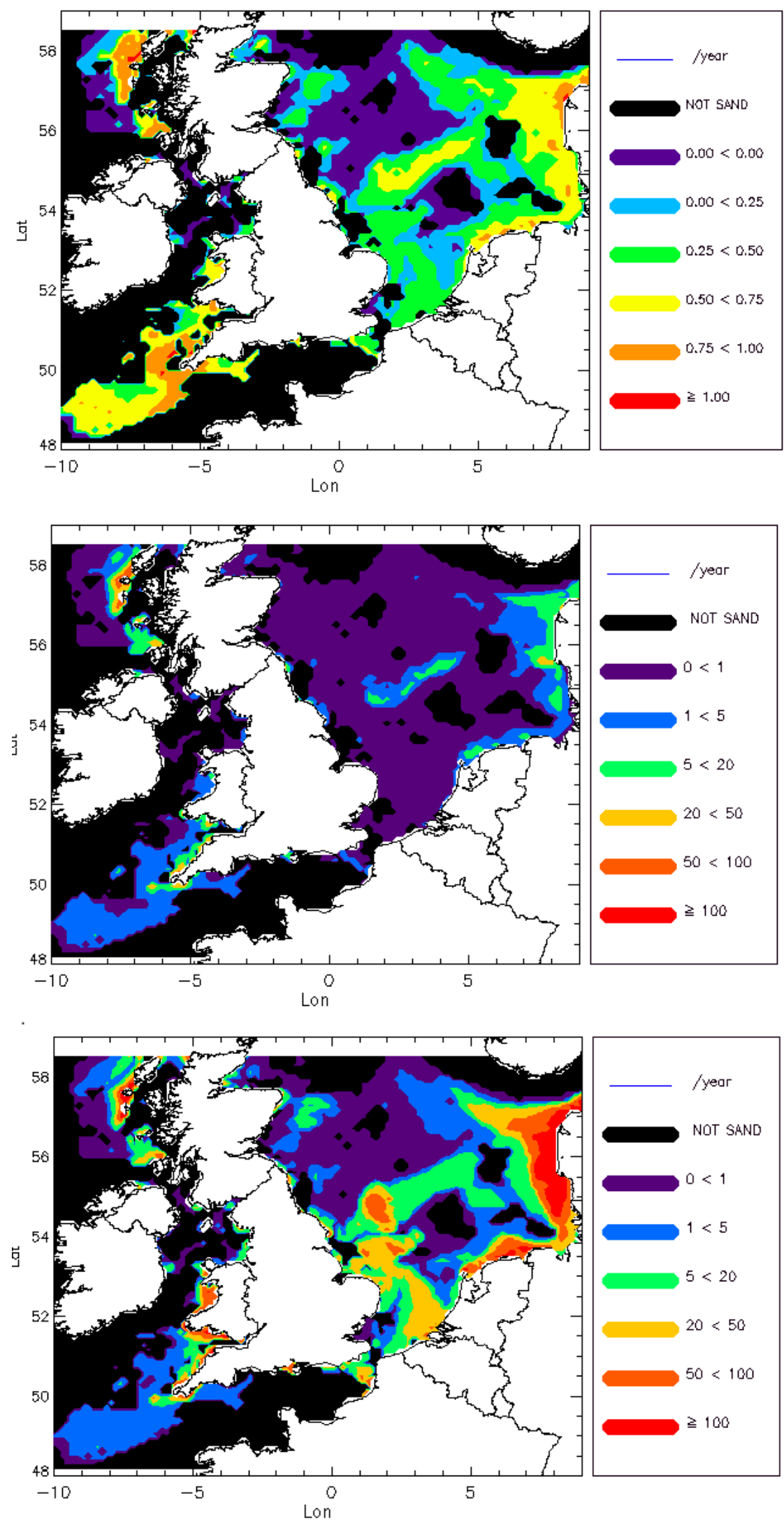

2 Figure 18: Disturbance at $5 \mathrm{~cm}$ for sand beds: a) Probability that disturbance occurred at least once in year; b) Median 3 disturbance frequency ; c) Range of disturbance frequency (Max-Min). 


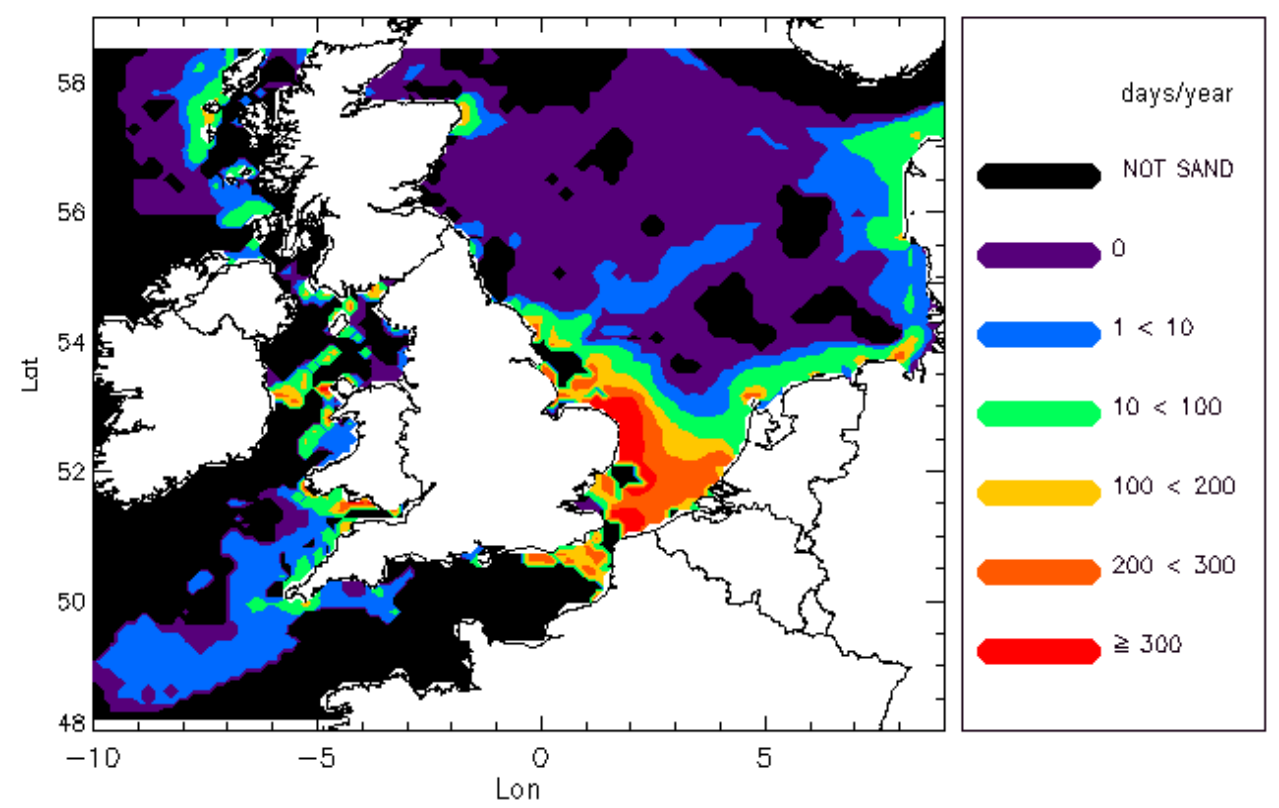

Figure 19: Median disturbance frequency at $5 \mathrm{~cm}$ if megaripples are included in addition to wave and current generated bedforms.

\subsection{Disturbance over gravel substrates}

For areas classed as gravel, the number of days a year disturbance by wave and current occurred was based on determining the number of days on which the local Shield values exceeded the threshold for movement. Taking account of the uncertainty in this threshold, results are presented in terms of the same quantities, $P_{>0}, N_{50}$ and the Range as for sand substrates. Unlike the sand case, no attempt was made to assign a depth to the disturbance.

Results are first shown assuming the median gravel diameter can be predicted from the measured sand/gravel ratio using Equation 7. With this assumption $\mathrm{P}_{>0}$ is greater than a half for $73 \%$ of the region classified as gravel (Figure 20a). The median disturbance frequency varies from less than five in deeper regions in the English Channel and Irish Sea to greater than 50 in shallow regions along UK east coast (Figure 20b). However uncertainty is relatively high in regions with high predicted disturbance frequency (Figure 20c).

Uncertainty in predicting gravel disturbance was compounded by not having the distribution of gravel size but having to infer it. A crude assessment was made of the additional uncertainty entailed. If $\bar{D}=\hat{D}_{\text {gravel }}$ is the diameter estimated from Equation 7, calculations were carried out for gravel diameters 0.5, 1.0 and 2.0 times $\bar{D}$. The percentage of the gravel region with a non-zero probability of disturbance decreased from 97 to 88 to 67 for gravel diameters given by $0.5 \bar{D}, 1.0 \bar{D}$ and $2.0 \bar{D}$ respectively. Similarly the percentage area subject to $\geq 0.5$ probability of disturbance decreased from 93 to 73 to 52 .

\subsection{Disturbance over mud substrates}

Based on the assumed range of stress thresholds for (type II erosion) bed failure, bed disturbance over muddy substrates appears to be an unlikely occurrence. Figure 21 shows the probability of disturbance occurring on at least 1 day of the year. The reader is reminded that this probability is broadly the proportion of runs in the ensemble for which a non-zero disturbance area was predicted at a given location. Only the region of muddy sand in the eastern Irish Sea appears to be a location where disturbance is likely. 

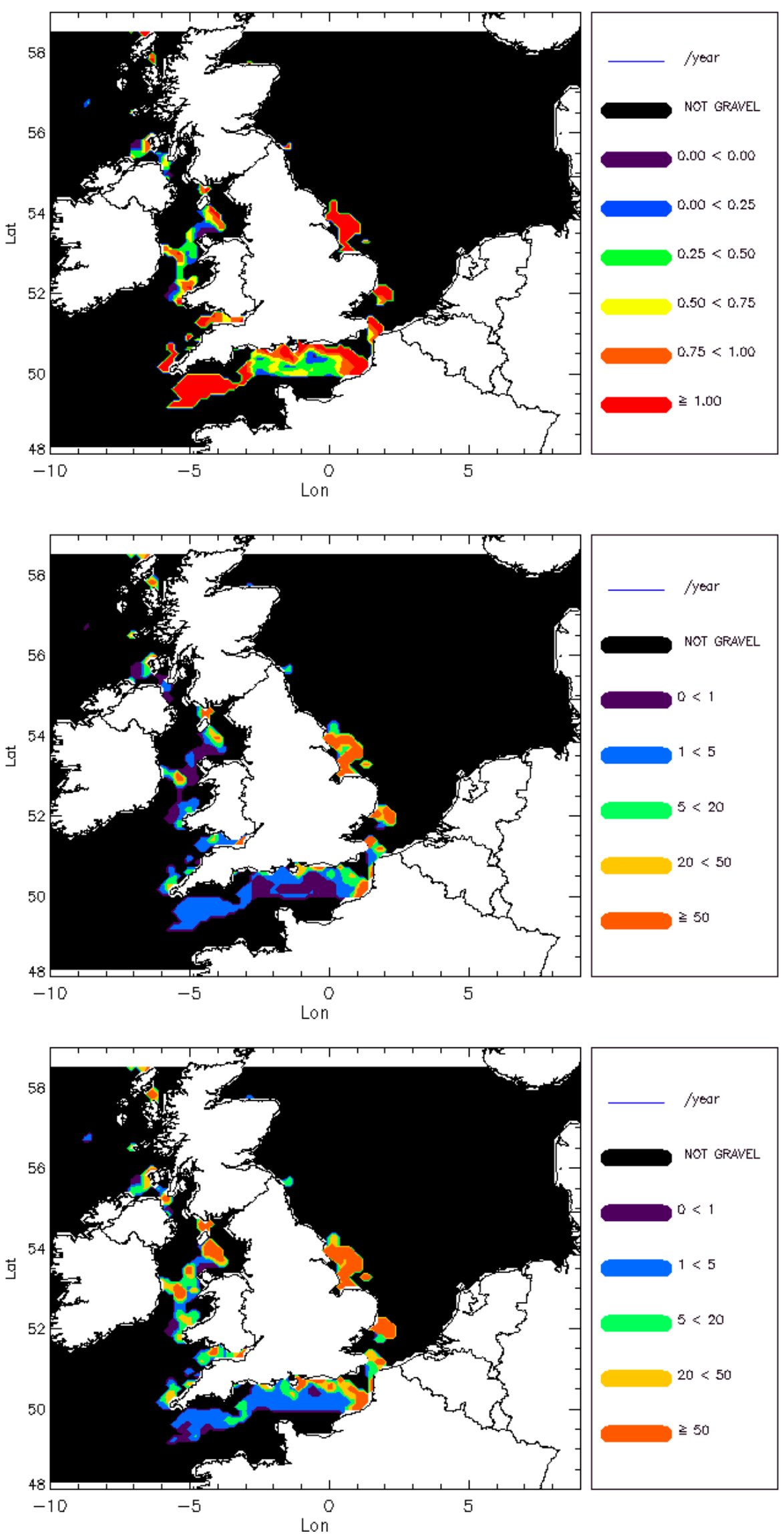

Figure 20: Gravel bed, disturbance frequency: a) probability that disturbance occurred at least once in year; b) median disturbance frequency; c) Range of disturbance frequency. Underlying grain size predicated from Equation 7. 


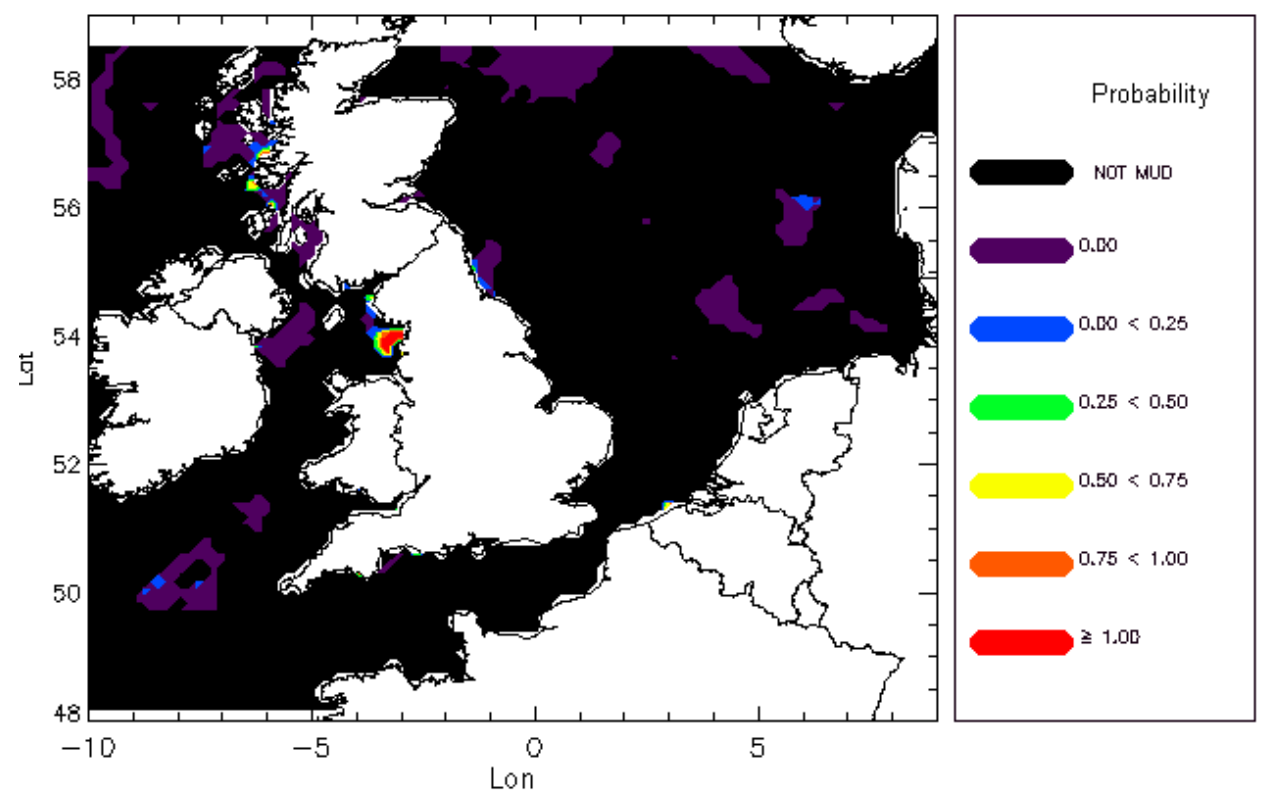

Figure 21: Muddy bed. Probability that disturbance occurred on at least one day during year (meteorological data for 2008).

\section{Discussion}

\subsection{Sand substrates}

Disturbance due to current ripples appears to be confined to the top $1 \mathrm{~cm}$ or so of sediment. Where tidal currents regularly exceed the threshold for sediment motion, shallow surface disturbance will be a semi-continuous process driven by tidally generated current ripples. This will occur over much of the southern North Sea, English Channel and Irish Sea. Where tidal stresses are generally below movement thresholds, shallow current ripple disturbance will be episodic and driven by storm events.

Larger, current-generated dune or megaripple bedforms were predicted to occur at many locations, particularly where strong tidal currents occur. However, there is some controversy surrounding the nature of these bedforms on the continental shelf. For predictive purposes there are two aspects to consider: conditions for occurrence and bedform dimension assuming occurrence. Southard \& Boguchwal (1990) in their synthesis of data on current generated bedform regime boundaries explicitly include water depth as one of the independent variables. Johnson et al. (1981) consider megaripples to be small sand waves and their predictive relationship that we use here is supposed to be applicable to both megaripples and the much larger sand wave bedforms that we do not consider (see for example Hulscher \& van der Brink, 2001). Ashley (1990) recognises only two current-generated bedform types, namely ripples and dunes. These are distinguished partly on size, but more fundamentally by the interaction with the free surface and an assumed size scaling with water depth for the dune mode. Some theoretical support for this comes from Richards (1984) who indeed shows two modes of bed instability that he identifies with ripples and dunes respectively, only the latter depending on flow depth (see also Colombini \& Stocchino, 2011). However Richards (1984) also suggests the possibility of an intermediate mode generated by ripple roughness and independent of flow depth that he tentatively identifies with intermediate size megaripple bedforms (see also Idier et al., 2004). Bartholdy et al. (2005) also question the assumption that all intermediate sized dune features scale with water depth and instead propose a bedform height relationship that is independent of water depth (Equation 13). Carle \& Hill (2009) also found no relationship with water depth for the large current-generated bedforms they observed. It is noted that neither of the two formulae used in this study to predict megaripple/dune occurrence have an explicit dependence on water depth despite both ultimately deriving from laboratory flume data. In conclusion, the situation with regard to dune/megaripple occurrence on the deeper continental shelf is unclear and the relationships used here, although having some independent validation, have only tentative support either theoretically or experimentally. This situation is a consequence of three unresolved but interrelated questions: 1) what is the nature of megaripples, 2) how relevant are flume studies of dune formation in very shallow water to predicting these features in deeper shelf seas, and 3) whether water depth should enter into predictive relationships for intermediate size bedforms in deep water. 
Notwithstanding these theoretical considerations, both the relationships for predicting sand wave/megaripple occurrence used in this study gave similar results for the spatial distribution of this bedform type. The relationship given by Equation 12 was shown by Johnson et al. (1981) to fit the known North Sea sand wave distribution well. Both this relationship and that suggested by Soulsby \& Whitehouse (2005) (Equation 11) also appear to match closely megaripple occurrence indicated on charts (BGS, 1987). A further verification is provided by Idier et al. (2002) who observed megaripple features migrating with tidal currents in the Dover Straits near the French coast and close to regions where both predictors indicate megaripples should occur.

Wave ripple heights were found to be significantly larger than current ripple heights, although values appear to be strongly influenced by the choice of wave ripple predictor. The formula of O'Donoghue et al. (2006) (ODWR) predicted maximum wave ripple heights of over $10 \mathrm{~cm}$ in the vicinity of west-facing UK and Danish coasts.. Assuming a steepness ratio of 0.15 , typical of wave ripples, these extreme ripple heights imply wavelengths of 50$60 \mathrm{~cm}$ and in the range commonly classified as LWR (Li \& Amos , 1998). More generally the ODWR ripple formula gave maximum heights of 4-8 cm. The Soulsby \& Whitehouse (2005) (SW) formula gave maximum ripple heights that were generally at least $2 \mathrm{~cm}$ lower. It is likely that predictions of extreme, rather than say average, height is perhaps a particularly stringent test of a ripple predictor and also most likely to show differences between different formulations. One reason for the difference between the formulae seems to be the nature of the dependence on wave period. The ODWR formula generally leads to an increase in ripple height with wave period due to the scaling of the height with wave excursion. The SW formula also scales ripple height with wave excursion but has a secondary dependence via the non-dimensional ratio of wave excursion with grain size. In the SW formula the two dependences tend to work in opposite directions leading to little or no increase in ripple height with wave period for fixed wave orbital speed. Another difference was the transition from 3D to larger 2D ripples for sand diameters greater than $0.25 \mathrm{~mm}$ included in the ODWR formula but not in the SW formula. The south western tip of England shows a particular large effect because of the occurrence of large grain sizes here combined with exposure to long period waves. Additional experimental analysis of wave ripple dimensions under long period waves and examination of the possible transition between 2 and 3 dimensional ripple forms would appear to be important. Because flume size limits the wave periods that can be studied in the laboratory, an alternative approach might be field observations of ripple heights under long period waves typical for offshore of west-facing European coasts. Although field validation of ripple prediction is outside the scope of this study, we note that for ripple bedforms such validation is difficult because: 1) ripples are generally too small for remote detection using side-scan sonar and similar acoustic methods; 2) their dynamic nature means that any single observation is a snapshot. This suggests long term deployment of near bed landers with instruments for visual or acoustic discrimination of small scale bedforms may be the most appropriate approach (e.g. Li \& Amos, 1998; Williams et al., 1998).

There seems to be increasing scatter in measured wave ripple heights under more extreme wave conditions. Nielson (1981) acknowledges this in proposing separate formulae and identifying the larger values with laboratory measurements and the smaller values with field conditions. This effect is also apparent in composite data sets presented by Pedocchi \& Garcia (2009) and Soulsby \& Whitehouse (2005) (Figure 16b). Suggested explanations for the scatter include the use of monochromatic waves in laboratory work contrasting with irregular waves in the field. Marsh et al. (1999) used wave spectra in their laboratory experiments and found generally poor agreement with the ripple predictors they tested. They hypothesised this was due to larger waves fixing the ripple scale that subsequent smaller waves could not alter, thus breaking the assumption that ripples are in (approximate) equilibrium with the prevailing wave regime. However, O'Donoghue et al. (2006) claim reasonable predictability under laboratory-produced irregular waves, provided wave orbital velocity was calculated from the average of the highest $10 \%$ of waves in the spectrum. Other explanations for the large scatter in the data and possible differences between laboratory and field conditions include: 1) ripples may not have reached equilibrium, 2) presence of currents in the field observation that might inhibit formation of large ripples, 3) water depth effects in flumes. The results of the present study suggest a further explanation; that the scatter in data at large mobility number might be due to the near simultaneous occurrence of two distinct bedform types - a washout ripple regime and LWR. The inclusion of both bedform types in the modelling allows a qualitative reproduction of the observed data (Figure 16). Additional support for the occurrence of this bedform type is suggested by the flume studies of Pedocchi \& Garcia (2009) where, under the largest waves, they appear to observe both standard wave ripple forms and large rounded bed forms reminiscent of the rounded 'hummocky' bedforms characteristic of the LWR as described by Li \& Amos (1999) under storm conditions. If LWR formation is the explanation for the scatter in data at high mobility number, we speculate that a possible reason for the difference in laboratory and field measurements is that the transition to LWR typically occurs at lower threshold 
in flumes, perhaps due to shallow water or free surface effects. Unfortunately, this would then call into question the particular threshold value used here to predict LWR occurrence, since that was based on flume data. Nevertheless, if the criterion used to predict LWR occurrence is assumed to be approximately correct under field conditions, then for the year of data used in this study LWR were predicted to occur over large parts of the continental shelf (Figure 15). In fact, discounting megaripples, LWR, where they occur, generally constituted the main source of disturbance to depths greater than $5 \mathrm{~cm}$.

The uncertainty analysis yields a cumulative distribution function for the disturbance frequency. However, this is relative to the choice of a given predictor formula for the average height. Thus the total uncertainty is compounded by the difference in mean heights predicted from alternative wave ripple formulae. Only certain specific areas of uncertainty were included in the analysis. For example the sensitivity to modelled wave and current forcing was not investigated nor uncertainty in thresholds for transition from ripples to megaripples/dunes and wave ripples to LWR. Even ignoring this, the cumulative distribution function often appears rather broad suggesting that predictability of the disturbance frequency appears to be poor, especially at sediment depths near the maximum allowed by a given wave ripple predictor. If a particular location is of interest it is recommended that the full spread of ensemble predictions be examined, including alternative ripple prediction formulae, to provide an idea of the uncertainty rather than relying on summary statistics such as the median or range.

\subsection{Gravel substrate}

Assuming gravel diameters can be estimated reliably from the correlation with the gravel/sand ratio (Equation 7) the results indicate a significant proportion of area classified as gravel has a probability of disturbance $>0.5(73 \%$ of the area has a $\geq 0.5$ probability of disturbance on at least one day). Gravel regions which appeared to have a high probability of disturbance and a large disturbance frequency include those offshore of East Anglia and the coastal strip along the English south coast. Areas with a low probability of disturbance include the deeper parts of the central English Channel and the southern Irish Sea.

There are important sources of uncertainty in the present predictions of disturbance over gravel substrates, including: 1) lack of gravel size information for the European continental shelf, 2) scatter in measurements of the movement threshold, 3) uncertainty about the choice of representative wave stress in a wave spectrum. The sensitivity of results to the first two effects was considered in this study. Regions of high disturbance frequency also seem to be associated with a large range in predictions due to uncertainty in the movement threshold (Figure 20 ) and the limited knowledge of gravel size distribution (Figure 21a,b,c). Compared with sandy regions these uncertainties imply a significant limit on the degree of confidence that can be attached to predictions. Nevertheless, some useful information can be obtained; for example at many locations there is a relatively high confidence that some disturbance will occur and also a reasonable estimate of the disturbance frequency. In addition the median frequency may give a good relative measure between locations, even if the large spread values suggest it may be poor as a typical value.

\section{$4.3 \mathrm{Mud} / \mathrm{muddy}$ sand}

Areas classified as mud in this study generally have a mud content of less than $20 \%$. Mitchener \& Torfs (1996) report a transition from non-cohesive to cohesive behaviour with mud content in the range of $3 \%$ to $15 \%$, so it would not be appropriate to treat these regions as non-cohesive sand. Nevertheless it is unlikely that these areas would exhibit behaviour ascribed to pure mud beds and so the results presented here are tentative. The most robust result would appear to be that the mud region potentially most exposed to wave action is in the eastern Irish Sea. However given the low resolution of the model and that the region indicated is muddy sand rather than pure mud this result needs to be treated with caution. Nearly all other muddy areas appear to be in deep areas not exposed to stresses sufficient for cohesive bed failure (type II erosion), even if these are assumed to be at the low end of the scale $\left(\sim 5 \mathrm{Nm}^{-2}\right)$.

\subsection{Gaps in knowledge}

An important outcome is the identification of important gaps in knowledge. A suggested list of topics for further research, chosen on the basis of their importance for reducing uncertainty in predicting depths of natural disturbance, is given here: 
1. Clarification is needed on the nature of megaripple sized bedforms, their relationship to water depth and with other bedforms such as ripples and sand waves.

2. Research is still required on wave ripple prediction (despite many previous studies) particularly under long period waves and for prediction of the largest ripples. Collection of data in the field rather than reliance on flume data would help resolve the issue of how applicable laboratory-derived relationships are, and how bedform predictions are best made when a wave spectrum is present.

3. Confirmation of the existence, threshold of occurrence and the properties of Large Wave Ripples under field conditions appear rather important.

4. A better knowledge of gravel sizes on the European continental shelf is essential.

5. A better understanding of the thresholds for gravel movement under a range of wave and current conditions is highly desirable.

6. Development of formulae for predicting the occurrence and height of gravel bedforms is needed in order to assess the depth of gravel disturbance.

7. Further study of the behaviour of mud sand mixtures (particularly at low mud content) is required, focussing on the transition from non-cohesive behaviour to cohesive behaviour and thresholds for mass erosion at high shear stress.

\subsection{Biological implications}

This study has focussed on physical reworking of the bed. A question arises concerning the broader biological and biogeochemical implications. Many studies have looked at biological disturbance in the context of trawling disturbance (e.g. Kaiser \& De Groot, 2000; Fonteyne, 2000; Jennings et al., 2001a,b) or aggregate extraction (e.g. Kenny \& Rees, 1996; Newell et al,. 2004; Cooper et al. 2008). The general assumption is that organisms adapted to live in areas of high natural disturbance may be more resilient to other forms of physical disturbance. Resilience in disturbed regions might come about by selection for fast-growing opportunistic species, which quickly recolonise disturbed areas and are able to reach sexual maturity before the next disturbance event. These species typically display small-size, short longevity and planktonic larval production traits. Alternatively, normal naturally-disturbed habitats may favour species which display traits that pre-adapt them to withstand the disturbance such as hard shells, deep-burrowing and high mobility. When comparing the relative impact on benthic organisms of natural and trawling disturbance, there is more potential for physical damage from the direct impact of a beam trawl than the formation of, say, a $5 \mathrm{~cm}$ high ripple over a period of several minutes. Therefore, adaptations to withstand natural disturbance, such as hard shells, might not be suitable to withstand the direct hit of a beam trawl. Other strategies such as evasion and rapid re-colonisation might be better suited to withstand fishing disturbance. These aspects need to be taken into account when attempting to directly compare natural disturbance and physical disturbance caused by anthropogenic impacts.

\section{Summary and conclusions}

A methodology for estimating the number of days in a year physical disturbance of the sea bed occurs due to wave and currents has been developed. Required inputs are seabed bathymetry, bed type and grain size data, together with time series of high resolution wave and current forcing. A simple Monte Carlo approach was used to assess certain aspects of the uncertainty associated with the predictions. For sand beds the variation in disturbance frequency with sediment disturbance depth could be calculated based on predicting the occurrence and size of small scale bedforms. For mud and gravel beds, a disturbance depth was not assigned. The method was applied to a region covering the North Sea, English Channel, Irish Sea and part of the eastern Celtic Sea. The results allow a broad understanding of the location and frequency of physical bed disturbance due to natural hydrodynamic processes. The main results are summarised as follows.

Sand substrates:

1. Current ripples cause disturbance only to the surface sediment (typically $\leq 1 \mathrm{~cm}$ ) and in regions with strong tidal currents this can be an almost continuous process. Elsewhere current ripple formation will be intermittent associated with extreme tides or wind generated currents.

2. Dunes/megaripples were predicated to occur in regions exposed to strong tide or wind-driven currents. In regions of very strong tides these bedforms may be almost continuously active. Disturbance depths greater than $10 \mathrm{~cm}$ were predicted based on empirical relationships. 
3. Where dunes/megaripples are not present, wave driven bedforms control disturbance at depths greater than $1 \mathrm{~cm}$ below the mean seabed level. Estimates of wave ripple disturbance depth were found to be sensitive to the choice of ripple predicator. The ODWR formula generally gave maximum annual disturbance depths in the range $2-4 \mathrm{~cm}$ (ripple heights $4-8 \mathrm{~cm}$ ). The maximum values from the SW formula were generally about half this. The difference appeared to be connected with the dependence on wave period.

4. Large Wave Ripples (LWR) were generally found to dominate seabed disturbance at depths greater than $5 \mathrm{~cm}$ if megaripples are discounted. Based on the median of the Monte Carlo simulations, maximum annual LWR disturbance depths in excess of $6 \mathrm{~cm}$ were predicted, usually occurring off west-facing coasts. Elsewhere, maximum LWR disturbance depths of $4-5 \mathrm{~cm}$ were typical.

5. If megaripples are excluded, median estimates of disturbance frequency for most locations were less than 50 and 20 days per year respectively at $3 \mathrm{~cm}$ and $5 \mathrm{~cm}$ below the seabed surface. Areas of higher disturbance included the Dogger Bank and offshore of west facing coasts.

6. If megaripples were included in the analysis, disturbance due to these bedforms of at least $5 \mathrm{~cm}$ on more than 100 days in a year were predicted in regions of strong tides.

7. Uncertainties in predicting bedform height generally lead to a large spread in predicted disturbance frequency relative to the median.

Gravel substrates:

1. Based on median estimates, areas classified as gravel were predicted to be subject to disturbance with frequencies in excess of 50 days per year at many locations.

2. Very wide bounds on frequency of disturbance were found due to a combination of the uncertainty associated with threshold conditions and lack of measured gravel size data for the European continental shelf.

Mud substrates:

1. Almost no areas classified as mud were found to exceed even the lower stress threshold for bed failure $\left(5 \mathrm{Nm}^{-2}\right)$ based on extreme waves. Locations showing possible disturbance included a small part of the eastern Irish Sea and a few isolated points in the Celtic and North Sea and off the Scottish west coast.

\section{Acknowledgements}

Defra is gratefully acknowledged for the support of this work under contracts AE1224, A1148, E5301 and the Marine Aggregate Levy Sustainability Fund under contract MEPF 09-P114. The views expressed are those of the authors and do not reflect the policies of the funding department. The comments of two anonymous referees that helped to considerably improve the final manuscript are acknowledged.

\section{References}

Amos, C.L., Li, M.Z. and Choung, K-S., (1996). Storm-generated, hummocky stratification on the outer Scotian shelf. Geo-Marine Letters 16, 85-94.

Amos C.L., Bowen A.J., Huntley D.A., Judges J.T., Li M..Z., (1999). Ripple migration and sand transport under quasiorthogonal combined flows on the Scotian shelf. Journal of Coastal Research 15(1), 1-14.

Ashley, G. M., 1990. Classification of large-scale subaqueous bedforms: a new look at an old problem. Journal of Sedimentary Petrology 60(1), 160-172.

Basford, D.J., Eleftheriou, A., Davies, I.M., Irion, G., Soltwedel, T., (1993). The ICES North Sea benthos survey: the sedimentary environment. ICES Journal of Marine Science 50(1), 71-80.

Bartholdy, J., Flemming, B.W., Bartholoma, A., Ernstsen, V.B., (2005). Flow and grain size control of depthindependent simple subaqueous dunes. J. Geophys. Res. Earth Surf.110, F04S16.

BGS 1987 Seabed sediments around the United Kingdom. South sheet. 
Brown, E.J., B. Finney, and S. Hills. (2005). Effects of commercial otter trawling on benthic communities in the southeastern Bering Sea. American Fisheries Society Symposium 41: 439-460.

Buffington, J. M. Montgomery, D. R. (1997). A systematic analysis of eight decades of incipient motion studies, with special reference to gravel-bedded rivers. Water Resources Research, 33(8):1993-2029.

Carle, L. and P. R. Hill (2009). "Subaqueous Dunes of the Upper Slope of the Fraser River Delta (British Columbia, Canada)." Journal of Coastal Research: 448-458.

Carling, P. A., K. RIchardson, et al. (2005). "A flume experiment on the development of subaqueous fine-gravel dunes from a lower-stage plane bed." Journal of Geophysical Research: Earth Surface 110(F04S): 05-[15pp].

Coggan, R., Diesing, M. (2011). The seabed habitats of the central English Channel: A generation on from Holme and Cabioch, how do their interpretations match-up to modern mapping techniques? Continental Shelf Research, 31: S132-S150

Coggan, R., Barrio Frojan, C. R. S., Diesing, M., Aldridge, J. (2012). Spatial patterns in gravel habitats and communities in the central and eastern English Channel. Estuarine, Coastal and Shelf Science, 111: 118-128

Colombini M., Stocchino (2011). Ripple and dune formation in rivers. Journal of Fluid Mechanics, 673, pp 121131 doi: $10.1017 /$ S0022112011000048

Cooper, K.M., Barrio Frojan, C.R.S., Defew, E., Curtis, M., Fleddum, A., Brooks, L.,Paterson, D.M. (2008) Assessment of ecosystem function following marine aggregate dredging. Journal of experimental Marine Biology and Ecology, 366:82-91

De Alteris J, Skrobe L, Lipsky C. (1999). The significance of seabed disturbance by mobile fishing gear relative to natural processes: a case study in Narragansett Bay. In: Benaka L, editor. Fish Habitat: Essential Fish Habitat and Rehabilitation. Bethesda, MD: American Fisheries Society; p. 224-237. American Fisheries Society, Symposium 22.

Diesing, M., Coggan, R., and Vanstaen, K. (2009). Widespread rocky reef occurrence in the central English Channel and the implications for predictive habitat mapping. Estuarine, Coastal and Shelf Science, 83: 647-658

Diesing, M., Stephens, D., Aldridge, J. (2013). A proposed method for assessing the extent of the seabed significantly affected by demersal fishing in the Greater North Sea. ICES Journal of Marine Science, 70 (6), 1085-1096

Dinehart, R. (1992), Evolution of Coarse Gravel Bed Forms: Field Measurements at Flood Stage, Water Resour. Res., 28(10), 2667-2689

Doucette, J. S. and T. O'Donoghue (2006). Response of sand ripples to change in oscillatory flow. Sedimentology 53(3): 581-596.

Giménez-Curto, Luis A.; Corniero Lera Miguel A. (1996) Oscillating turbulent flow over very rough surfaces, Journal of Geophysical Research, Volume 101, Issue C9, p. 20745-20758

Eggleton J., Dolphin T., Ware S., Bell T., Aldridge J., Silva T., Forster R.,Whomersley P., Parker R., Rees J., (2011). Natural variability of REA regions, their ecological significance \& sensitivity. MEPF-MALSF Project 09-P114. Cefas, Lowestoft, 171 p.ISBN: 9780907545422

Fenton, J. D. and J. E. Abbott (1977). "Initial Movement of Grains on a Stream Bed: The Effect of Relative Protrusion." Proceedings of the Royal Society of London. A. Mathematical and Physical Sciences 352(1671): 523-537.

Fonteyne, R., (2000). Physical impact of beam trawls on seabed sediments. In: M. J. Kaiser and S. J. de Groot (eds.), Effects of fishing on non-target species and habitats: biological conservation and socio-economic issues, Blackwell Science, Oxford, pp. 15-36. 
Forbes D. L., R. Boyd (1987). Gravel ripples on the inner Scotian Shelf. Journal of Sedimentary Research, v. 57, p. 46-54

Fredsфe, J.,( 1984). Turbulent boundary layer in wave-current motion. Journal of Hydraulic Engineering ASCE $110,1103-1120$.

FSBI (2001) Marine protected areas in the North Sea. Briefing Paper 1, Fisheries Society of the British Isles, Granta Information Systems, 82A High Street, Sawston, Cambridge CB2 4H, UK.

Hammond, F. D. C., A. D. Heathershaw, et al. (1984). A comparison between Shields' threshold criterion and the movement of loosely packed gravel in a tidal channel. Sedimentology 31(1): 51-62.

Hall, S.J., (1994). Physical disturbance and marine benthic communities: life in unconsolidated sediments. Oceanography and Marine Biology an annual review 32, 179-239.

Harris, P. T. and M. G. Hughes (2012). Predicted benthic disturbance regimes on the Australian continental shelf: a modelling approach. Marine Ecology Progress Series 449: 13-25.

Hemer M.A.,(2006). The magnitude and frequency of combined flow bed shear stress as a measure of exposure on the Australian continental shelf, Continental Shelf Research, Volume 26, Issue 11, August 2006, Pages 12581280 ,

Holt, J. T., James, D. J., 2001. An s coordinate density evolving model of the northwest European continental shelf: 1 model description and density structure. J. Geophys. Res. C 106, 14015-14034.

Hughes, M.G., Harris, P.T and Brooke, B.P. (2010). Seabed exposure and ecological disturbance on Australia's continental shelf: Potential surrogates for marine biodiversity. Geoscience Australia Record 2010/43, 78pp.

Hulscher, S. J. M. H. and G. M. van den Brink (2001). Comparison between predicted and observed sand waves and sand banks in the North Sea. Journal of Geophysical Research: Oceans 106(C5): 9327-9338.

Idier, D., Ehrhold, A., Garlan, T., (2002). Morphodynamique d'une dune sous-marine du détroit du pas de Calais. C.R. Geoscience 334, 1079-1085.

Idier, D., D. Astruc, et al. (2004). Influence of bed roughness on dune and megaripple generation. Geophysical Research Letters 31(13): L13214.

Jarke, J., (1956). Der Boden der Suedlichen Nordsee. Deutsche Hydrographische Zeitschrift 9, 1-9.

Jennings, S., Dinmore T. A., Duplisea D. E., Warr K. J., Lancaster J. E. ., (2001). Trawling disturbance can modify benthic production processes. Journal of Animal Ecology 70, 459-475.

Johnson, M.A., Stride, A.H., Belderson, R.H., Kenyon, N., (1981). Predicted sand-wave formation and decay on a large offshore tidal-current sand-sheet. In: Nio, S.D., Schüttenhelm, R.T.E., van Weering, T.C.E., eds., Holocene Marine Sedimentation in the North Sea Basin. Special Publication of the International Association of Sedimentologists 5, 247-256.

Kaiser, M.J., De Groot, S.J. (2000) The effects of fishing on non-target species and habitats: biological, conservation and socio-economic issues. Blackwell Science, Oxford. 416 pp.

Kalnay, E. and Coauthors, 1996: The NCEP/NCAR Reanalysis 40-year Project. Bull. Amer. Meteor. Soc., 77, 437471.

Kenny, A.J. \& Rees, H.L. (1996) The effects of marine gravel extraction on the macrobenthos: Results 2 years postdredging. Marine Pollution Bulletin, 32(8/9):615-622 
Kershaw, P. J., D. C. Denoon, D.S. Woodhead (1999). Observations on the redistribution of plutonium and americium in the Irish Sea sediments, 1978 to 1996: concentrations and inventories. Journal of Environmental Radioactivity 44(2-3): 191-221.

Komar, P.D. and Li, Z., 1988. Applications of grain pivoting and sliding analyses to selective entrainment of gravel and to flow-competence evaluations. Sedimentology, 35: 681-696.

Kostylev, V.E., C.G. Hannah, (2007), Process-driven characterization and mapping of seabed habitats, in Todd, B.J.,and Greene, H.G., eds., Mapping the Seafloor for Habitat Characterization: Geological Association of Canada, Special Paper 47, p. 171-184.

Langhorne D., Heathershaw A., Read A. (1986). Gravel bedforms in the West Solent, Southern England, GeoMarine Letters, 12-16

Li, M.Z., Amos, C.L., (1998). Predicting ripple geometry and bed roughness under combined waves and currents in a continental shelf environment. Continental Shelf Research 18, 941-970.

Li, M.Z., Amos, C.L., (1999). Sheet flow and large wave ripples under combined waves and currents: field observations, model predictions and effects on boundary layer dynamics. Continental Shelf Research 19, 637663.

Marsh S.W., Vincent C.E., Osbourne P.D.,(1999). Bedforms in a laboratory wave flume: an evaluation of predictive models for bedform wavelengths. Journal of Coastal Research 15(3), 624-634.

Mitchener, H., H Torfs, (1996). Erosion of mud/sand mixtures, Coastal Engineering, Volume 29, Issues 1-2, , Pages $1-25$,

Neill, S. P., Scourse, J. D., Uehara, K. (2010). Evolution of bed shear stress distribution over the northwest European shelf seas during the last 12,000 years. Ocean dynamics, 60(5), 1139-1156.

Newell, R.C., Seiderer, L.J., Simpson, N.M., Robinson, J.E., (2004). Impacts of marine aggregate dredging on benthic macrofauna off the south coast of the United Kingdom. Journal of Coastal Research, 20: 115-125.

Nielsen, P., (1981). Dynamics and geometry of wave-generated ripples. Journal of Geophysical Research 86, 6467-6472.

O'Donoghue T., J.S. Doucette, J.J. van der Werf, J.S. Ribberink, (2006). The dimensions of sand ripples in full-scale oscillatory flows, Coastal Engineering, Volume 53(12), 997-1012,

Ockenden, M.C. and Soulsby, R.L. (1994). Sediment transport by currents plus irregular waves. HR Wallingford Report SR 376, February 1994.

Osuna, P., Wolf J., (2004). Results from a one-year run of a wave model for the UK continental shelf. Proudman Oceanographic Laboratory, Internal Document No. 170.

Panagiotopoulos, I.; Sylaios, G.; Collins, M. B, (1994). Threshold studies of gravel size particles under the co-linear combined action of waves and currents. Sedimentology, 41(5) 951-962.

Paphitis, D. (2001). Sediment movement under unidirectional flows: an assessment of empirical threshold curves, Coastal Engineering 43, 227-245

Pebesma, E. (2004) Multivariate geostatisitcs in S: the gstat package. Computers and Geosciences,30, 683-691.

Pedocchi, F. and M. H. García (2009). "Ripple morphology under oscillatory flow: 1. Prediction." Journal of Geophysical Research: Oceans 114(C12): C12014.

Perigaud, C (1984). Erosion of cohesive sediments by a turbulent flow: Part II. High mud concentration. J. Theoretical. Applied. Mechanics, 3(4): 505-519. 
Richards K.J., (1980). The formation of ripples and dunes on an erodible bed. Journal of Fluid Mechanics 99(3), 597-618.

Soulsby R.L., Hamm L., Klopman G., Myrhuag D., Simons R.R., Thomas G.P., (1993). Wave-current interaction within and outside the bottom boundary layer. Coastal Engineering 21, 41-69.

Soulsby R. L., (1997), Dynamics of marine sands, Thomas Telford publications, London., 249 pp. ISBN 072772584 $\mathrm{X}$.

Soulsby R.L., Whitehouse R.J.S. (2005), Prediction of Ripple Properties in Shelf Seas, Mark 2. Predictor for Time Evolution, Final Technical Report ONR, TR154.

Southard, J. B., Boguchwal, L. A. (1990).Bed configurations in steady unidirectional water flows. Part 2. Synthesis of flume data. J. Sediment. Petrol. 60(5): 658-79

Smith, D., and J. F. A. Sleath (2005), Transient ripples in oscillatory flows, Continental Shelf Res., 25, $485\{501$.

Swift, D. J. P., A. G. Figueiredo, G. L. Freeland, and G. F. Oertel, (1983). Hummocky crossstratification and megaripples: a geological double standard? Journal of Sedimentary. Petrology 53, p.1295-1317.

Trimmer, M., J. Petersen, C. Mills, D. Sivyer, E. Young and R. Parker, (2005). Impact of benthic trawl disturbance on sediment biogeochemistry in the Southern North Sea. Marine Ecology Progress Series. Vol 298, pp 79-94.

Van der Molen J., (2002), The influence of tides, wind and waves on the net sand transport in the North Sea, Continental Shelf Res, 22, 2739--2762.

Williams J.J., Humphery J.D., Hardcastle P.J., Wilson D.J., (1998). Field observations of hydrodynamic conditions and suspended particulate matter in the southern North Sea, Continental Shelf Research 18(11), 1215-1233.

You, Z.J., (2009). The statistical distribution of nearbed wave orbital velocity in intermediate coastal water depth, Coastal Engineering 56, 844-852 